Review

\title{
Current Trends in Polymer Based Sensors
}

\author{
Giancarla Alberti ${ }^{1, *}\left(\mathbb{C}\right.$, Camilla Zanoni ${ }^{1}$, Vittorio Losi ${ }^{1}$, Lisa Rita Magnaghi ${ }^{1,2}$ (D) and Raffaela Biesuz ${ }^{1,2}$ \\ 1 Department of Chemistry, University of Pavia, Via Taramelli 12, 27100 Pavia, Italy; \\ camilla.zanoni01@universitadipavia.it (C.Z.); vittorio.losi@edu.unito.it (V.L.); \\ lisarita.magnaghi01@universitadipavia.it (L.R.M.); raffaela.biesuz@unipv.it (R.B.) \\ 2 Unità di Ricerca di Pavia, INSTM, Via G. Giusti 9, 50121 Firenze, Italy \\ * Correspondence: galberti@unipv.it
}

check for updates

Citation: Alberti, G.; Zanoni, C.; Losi, V.; Magnaghi, L.R.; Biesuz, R. Current Trends in Polymer Based Sensors. Chemosensors 2021, 9, 108. https://doi.org/10.3390/ chemosensors 9050108

Received: 30 March 2021

Accepted: 10 May 2021

Published: 13 May 2021

Publisher's Note: MDPI stays neutral with regard to jurisdictional claims in published maps and institutional affiliations.

Copyright: (C) 2021 by the authors. Licensee MDPI, Basel, Switzerland. This article is an open access article distributed under the terms and conditions of the Creative Commons Attribution (CC BY) license (https:/ / creativecommons.org/licenses/by/ $4.0 /)$.

\begin{abstract}
This review illustrates various types of polymer and nanocomposite polymeric based sensors used in a wide variety of devices. Moreover, it provides an overview of the trends and challenges in sensor research. As fundamental components of new devices, polymers play an important role in sensing applications. Indeed, polymers offer many advantages for sensor technologies: their manufacturing methods are pretty simple, they are relatively low-cost materials, and they can be functionalized and placed on different substrates. Polymers can participate in sensing mechanisms or act as supports for the sensing units. Another good quality of polymer-based materials is that their chemical structure can be modified to enhance their reactivity, biocompatibility, resistance to degradation, and flexibility.
\end{abstract}

Keywords: polymer-based sensors; natural polymers; synthetic polymers; polymer inclusion membranes; nanocomposite polymeric based materials UV-vis sensors; color analysis; humidity sensors; electrochemical devices; MIP-based sensors; wearable sensors

\section{Introduction}

A wide range of recently developed materials are polymers, and due to their different physico-chemical properties, they are useful in several applications. Currently, interest is devoted to polymers since they can change their properties (reversibly or irreversibly) under external inputs (for example, the presence of particular ions or bioactive molecules, $\mathrm{pH}$, temperature, light radiation, electric or magnetic fields, etc.). Polymers may appear as solids, solutions, gels, nanoparticles, or films. These materials can be adapted to specific tasks through their appropriate modification or synthesis to develop sensor devices (a device is a piece of equipment or a mechanism designed to serve a special purpose or perform a special function, so in this review, we used the term device as a "synonymous" of a solid-phase chemical sensor).

The literature of the last few years has reported several works on chemical sensors. Recent examples of polymer-based sensors have been related to human health monitoring, food safety, and environmental monitoring were described.

In general, traditional analytical methods required sophisticated instrumentation, trained personnel, and protocols not adapted for ready use by common people or in resource-limited areas. Consequently, developing cheap and user-friendly sensors, combined with high sensitivity, is of great importance.

For obtaining sensors and biosensors with better performance, polymer-based technologies are the most promising. The polymeric materials used in sensor devices include molecular imprinted polymers (MIP), conducting polymers and their composites, hydrogels, etc.

The polymer-based materials frequently applied in these kinds of sensors improve the recognition of target molecules, behave like supports for functionalities immobilization (e.g., dyes, fluorophores, metal nanoparticles), and by changing their physical or chemical 
characteristics, allow the detection of the target analytes. Another advantage of polymerbased sensors is the possibility of modifying their chemical properties tuning their reactivity, biocompatibility, flexibility, and resistance to degradation [1,2]

This review examines polymers in chemical sensing, describing groups of devices based on different kinds of polymer materials, distinguishing between natural and synthetic polymers.

For each category, we focus on detailing the polymers for different applications, highlighting the figures of merit of the devices, i.e., sensitivity, detection limit (LOD), quantification limit (LOQ), selectivity, and stability.

In Figure 1, an overview image is reported.

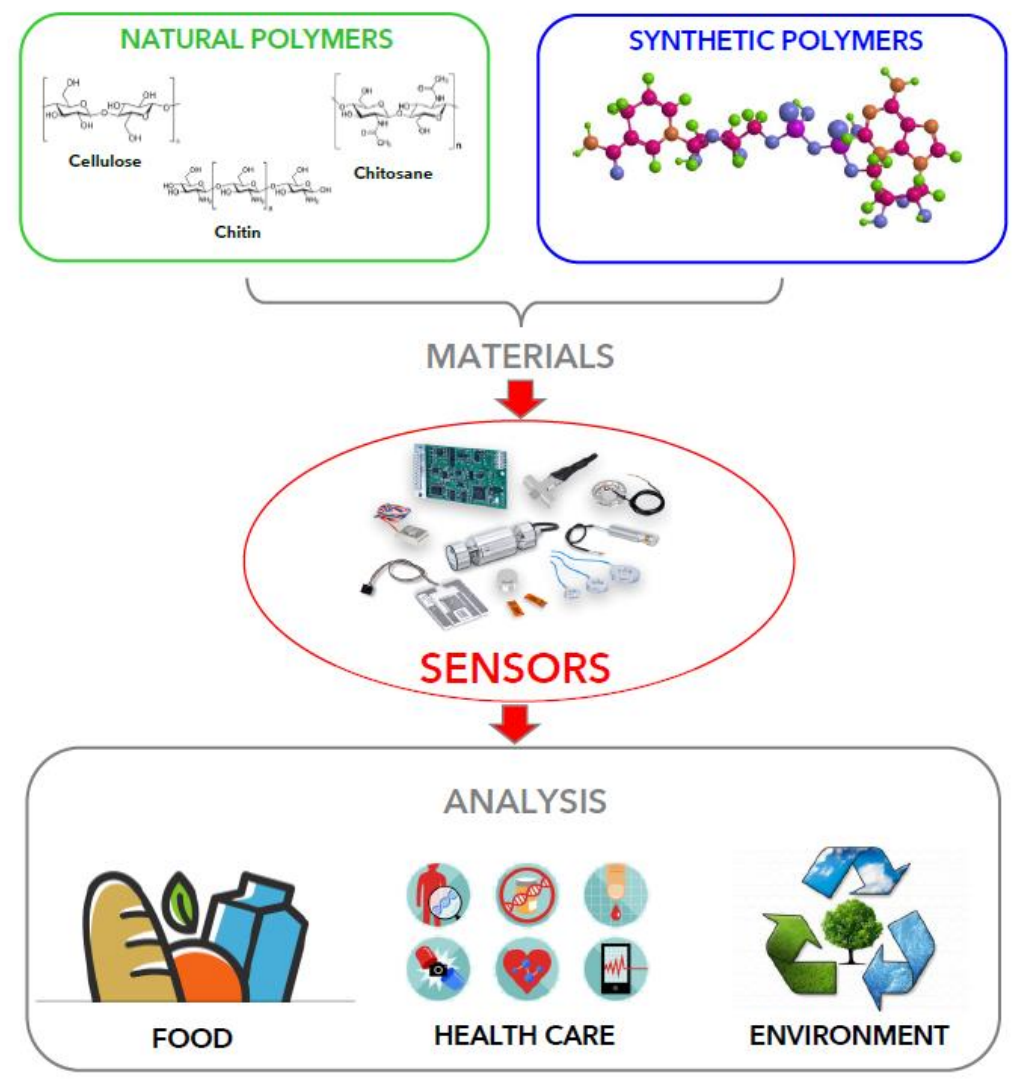

Figure 1. Overview image of polymer-based sensors described in this review.

\section{Natural Polymer-Based Sensors}

Natural polymers are macromolecules derived from animals or plants and are employed in several fields, for example, in aliments, pharmaceutics, cosmetics, and chemistry. These polymers are economical, tunable, readily available, biodegradable, and biocompatible. Unfortunately, they may be degraded by microorganisms, the synthesis is rarely reproducible, the hydration degree is variable, and metal ions may contaminate the polymer's surface [3].

Cellulose, hemicellulose, glucomannan, agar, starch, pectin, inulin, rosin, acacia gum have plant origin, while chitin, chitosan, and alginate have an animal origin [3].

Natural polymers may have different textures depending on the different nature of the monomers; for example, carboxymethyl cellulose (CMC) is water-soluble thanks to the hydrophilicity of the monomers when the molecular weight increases, CMC forms a hydrogel in solution. Cellulose is a polysaccharide insoluble in water, also known as cotton, when in the ultrapure formulation. Cotton is a fiber used principally in the textile field. Because of the different reticulation, natural polymers may have different textures, more fibrous or more hydrogel-like; for this reason, only limited biopolymers are applied in the sensors field. 
Cellulose is a biopolymer widely used in sensors obtained from wood and straw. This homopolymer comprises D-anhydroglucopyranose units linked by the (1-4) $\beta$-glucosidic bond (Figure 2) [4].

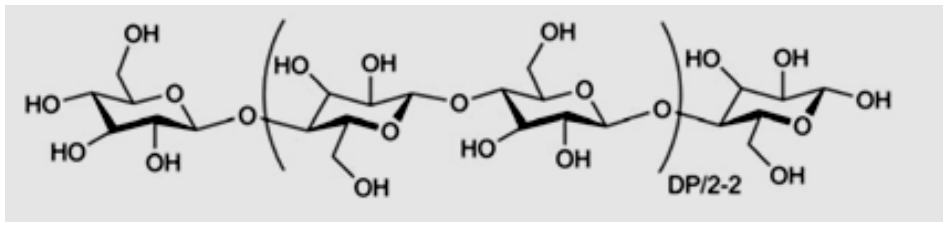

Figure 2. Cellulose structure (Reproduced with permission from [4], open access Creative Common CC licenced 4.0, MDPI).

Cellulose is colorless, odorless, adsorbent, hydrophilic, and the groups on its surface are easy to functionalize.

Paper is a convenient cellulose-based material for sensors. Commonly developed are colorimetric sensors due to the paper's bright, high-contrast, colorless background, suitable for well-appreciated color changes.

Alberti et al. [5] described a paper-based sensor for Fe(III) and V(IV) obtained by functionalization of cellulose with deferoxamine (DFO), a strong chelating agent that forms stable and colored complexes with these two cations.

The sensor, named DFO-paper, is prepared with a strategy originally proposed by Takagi et al. [6], consisting firstly of halogenation of the hydroxyling groups, followed by the reaction with DFO molecules (see Figure 3).

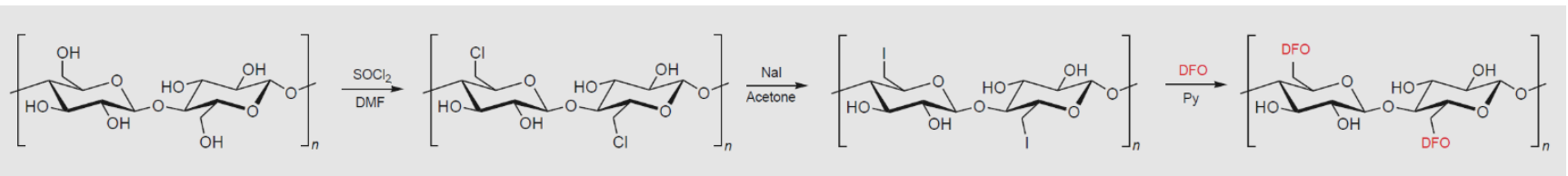

Figure 3. Synthesis scheme for the DFO-paper preparation. (Adapted with permission from [5], Copyright 2017 Springer Nature).

The sensor's colorimetric response to $\mathrm{Fe}(\mathrm{III})$ or $\mathrm{V}(\mathrm{V})$ in solutions allowed the detection with the naked eye and the quantification of both cations. Indeed, RGB parameters of the DFO-papers images after exposure to $\mathrm{Fe}(\mathrm{III})$ and $\mathrm{V}(\mathrm{V})$ solutions, acquired by a desktop scanner, are employed for metal ions quantification.

Biesuz and colleagues [7-10] developed low-cost colorimetric sensors based on the Colour Catcher ${ }^{\circledR}$ (CC), a commercial cellulose-based product used to prevent color run in the washing machine. The CC substrate was functionalized with different dyes to develop colorimetric devices for some metal ions, sulfur/thiols, and food spoilage detection. For example, in a recent paper [9], the CC was functionalized with two dyes: Eriochrome Black $\mathrm{T}$ (EBT) and 1-(2-pyridalazo)-2-naphthol (PAN). The first solid phase obtained, named EBT-CC, can detect $\mathrm{Ca}$ (II) and $\mathrm{Mg}$ (II), while the solid phase functionalized with PAN can be used for determining $\mathrm{Co}(\mathrm{II}), \mathrm{Ni}(\mathrm{II})$, and $\mathrm{Zn}(\mathrm{II})$. After contact with the cation's solution, these sensors change their color (see Figure 4).

The demand for biodegradable packaging films, biosorbents, and disposable sensors supported the development of new materials obtained from natural sources, mainly agricultural byproducts. Sugarcane bagasse is cellulose-rich waste from the sugar industry, and it is a great choice for preparing cellulose-based devices. For example, Guo W. et al. [11] developed a colorimetric device for detecting $\mathrm{Ag}+$ and $\mathrm{Cu}^{2+}$. It is prepared via a one-pot reaction by grafting the 2,5-dithiourea (DTu) onto bagasse-pulp cellulose. After contact with metal-ion solutions, this device displays color changes from white to yellow-red or to light grey in the presence respectively of $\mathrm{Ag}+$ and $\mathrm{Cu}^{2+}$. The advantages of the proposed sensor are simplicity, rapidity, and good selectivity for $\mathrm{Ag}+$ and $\mathrm{Cu}^{2+}$. 


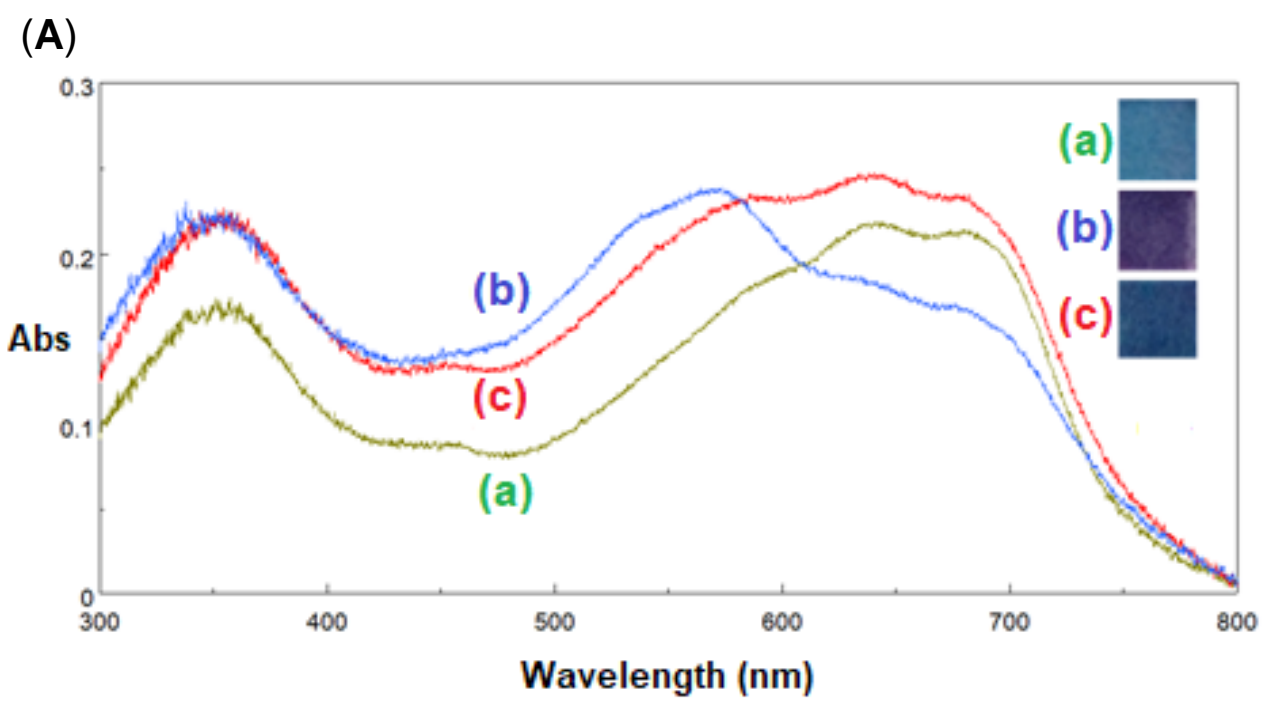

(B)

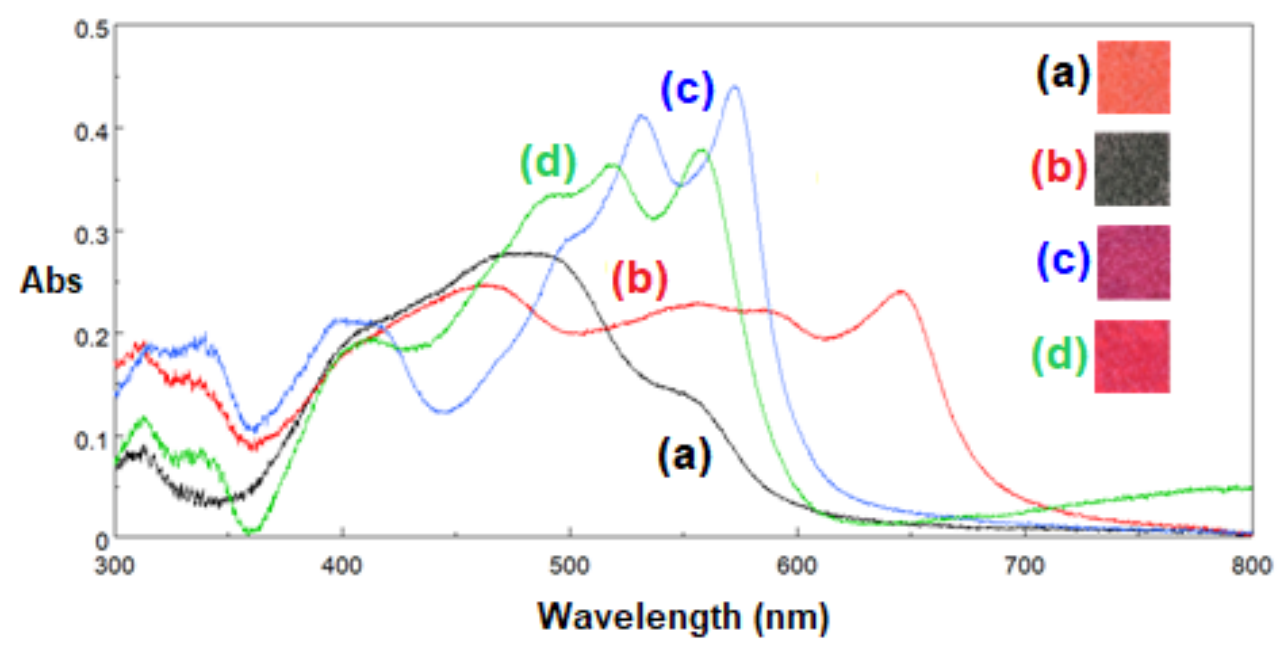

Figure 4. UV-vis spectra and images of: (A) EBT-CC before (a) and after equilibration in $\mathrm{Mg}$ (II) solution (b) or Ca(II) solution (c); (B) PAN-CC before (a) and after equilibration in $\mathrm{Co}(\mathrm{II})$ (b), $\mathrm{Ni}(\mathrm{II})$ (c), and $\mathrm{Zn}$ (II) (d) solutions. (Adapted with permission from [9], open access Creative Common CC licenced 4.0, Springer Open).

Nanocellulose obtained from nanofibers, nanocrystalline, or bacterial can be applied for obtaining disposable sensors. Starting from cellulose fibers of lignocellulosic resources (i.e., wood and agricultural residues), cellulose nanofibers (CNFs) can be isolated and purified by distinct mechanical or chemical processes [12].

Chauhan et al. [13] described an optical pH sensor based on a one-pot synthesis of nanocellulose functionalized with a dye. The nanocellulose is obtained from commercial microcrystalline cellulose of cotton fibers by hydrolysis with $64 \%$ sulfuric acid at $45^{\circ} \mathrm{C}$, for $45 \mathrm{~min}$. A Remazol dye [14] is covalently bound to the nanomaterial obtained.

The nanocellulose-dye gave stable suspensions that changed color from orange to purple after increasing the $\mathrm{pH}$ from acid to alkaline. After gluing with adhesive tape, a piece of the nanocellulose-dye film on a plastic strip, a disposable stick was obtained. It can sense $\mathrm{pH}$ changes reversibly and rapidly.

Another biopolymer widely used is chitosan. This macromolecule is a polysaccharide obtained from chitin's deacetylation, a molecule present in shellfish's exoskeleton [15].

Chitosan is a polymer with good adhesion properties, film ability, permeability towards water, high mechanical strength, and biocompatibility. Thanks to amines on the polymer's surface with $\mathrm{p} K_{\mathrm{a}}=6.3$, chitosan is applied as an ionophore in surface-modified sensors for anions [16] (Figure 5). 
a)

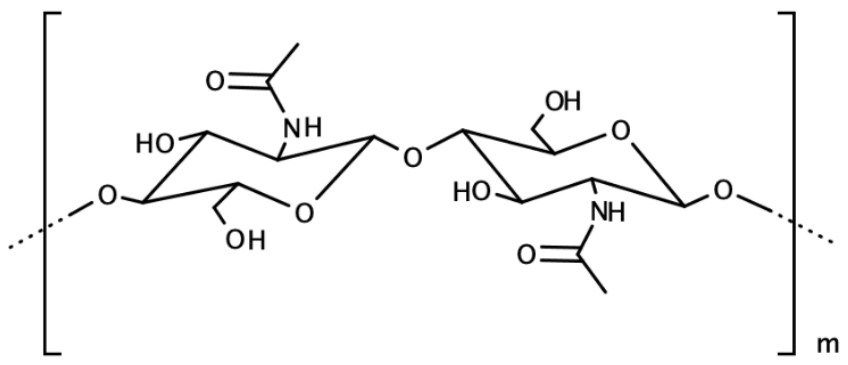

b)

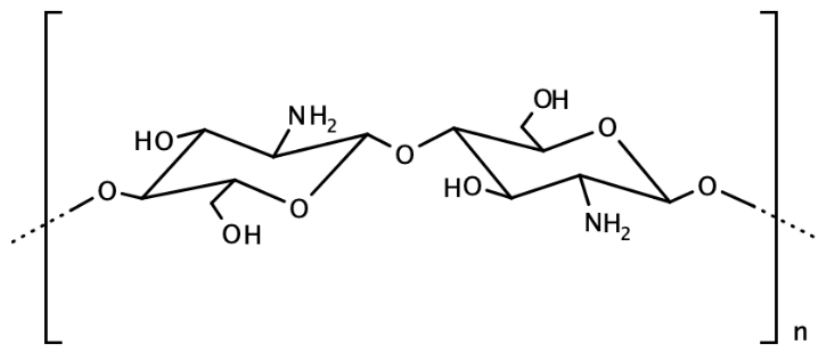

Figure 5. (a) Chitin and (b) Chitosan structures. (Adapted with permission from [16], Copiright 2020, ACS).

Xin et al. [17] developed a voltammetric chitosan-modified glassy carbon electrode for bromide detection in acid solutions (Figure 6).
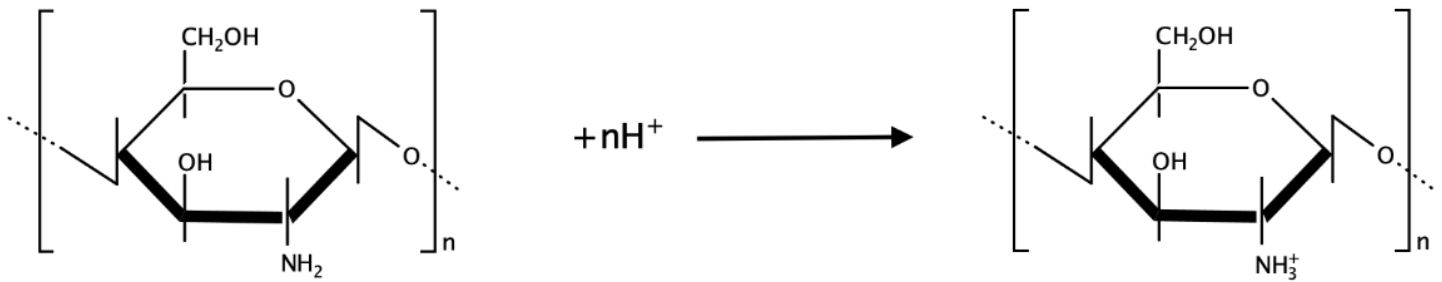

Figure 6. pH effect on chitosan. (Adapted with permission from [17], Copiright 2001, John Wiley and Sons).

A strong acid $\mathrm{pH}$ is necessary to obtain a good response; indeed, the amino groups are protonated in the $\mathrm{pH}$ range between 1.65-1.92, and they can attract more bromide. The detected current increases proportionally with the bromide concentrations. The method was applied for detecting bromide content in cetyltrimethylammonium bromide, tetrabutylammonium bromide, and wastewater, giving satisfactory results.

Darder et al. [18] developed a potentiometric sensor based on chitosan-clay nanocomposites to determine $\mathrm{CH}_{3} \mathrm{COO}^{-}$, tetraphenylborate, $\mathrm{NO}_{3}{ }^{-}, \mathrm{SCN}^{-}$, Benzoate, $\mathrm{Cl}, \mathrm{F}, \mathrm{Fe}(\mathrm{CN})_{6}{ }^{3}$, $\mathrm{Fe}(\mathrm{CN})_{6}{ }^{4}$. Chitosan is mixed in various percentages with clay to mitigate its well-known cations exchange properties. The mixture becomes an anion exchange material by increasing the concentration of chitosan. The system acquired electronic conductivity, adding graphite particles to the mix. It is important to stress that all the sensor materials are natural and with a low environmental impact.

In Kurnish et al. [19], the ability of chitosan to bound anions in solutions with low $\mathrm{pH}$ values was exploited to develop an ion-selective electrode (ISE) for chromate. In this case, chitosan was used as a carrier inside a PVC membrane.

Frequently chitosan is applied for electrode coatings to immobilize biological species. In this field, Magalhães and Machado [20] prepared a urea potentiometric biosensor based on urease immobilized on a chitosan membrane. Two electrodes were prepared following different procedures: (A) urea is immobilized to chitosan by a physical adsorption (B) the membranes obtained in point $A$ are reticulated with glutaraldehyde. In the first case, the membrane has a high activity, but the sensor's lifetime was around one month. In the second case, the reticulation with glutaraldehyde decreases the enzymatic activity, but the sensor's lifetime was around two months.

Nowadays, food safety problems are increasingly consumer concerns. During food storage, $\mathrm{pH}$ and microbes lead to deterioration and spoilage. There is a need for natural and biocompatible techniques to evaluate food quality. Chitosan itself or combined with other biomaterials could be applied in developing sensing films to evaluate $\mathrm{pH}$, enzymes, microbial metabolism, emission of gaseous products of food degradation. These films have several advantages; they can be small, lightweight, safe, and highly sensitive [21].

Currently, colorimetric sensors are the most popular. For example, in an interesting paper, [22] methylene blue (MB) was immobilized on a modified chitosan-based polymeric 
film to obtain an indicator of food conditions. The color of the film is blue under enough content of oxygen dissolved. However, it gradually turns from blue to white when oxygen is depleted by the microorganism's metabolism and the concomitant production of reducing substances. A small piece of the sensor can be inserted on the packaging film's inner face with a reference colors scale, so the consumers can directly observe by the naked eye the food quality.

Colorimetric chitosan-based $\mathrm{pH}$ sensors are also developed as indicators of food quality, safety, and freshness.

Microbial sensors were also promising since microbial growth increases the hazard to food safety. An interesting paper [23] describes a sensor based on chitosan hydrogel films with a self-reporting function for $\beta$-glucuronidase secreted by $E$. Coli bacteria. In this case, the fluorophore 4-methylumbelliferyl- $\beta$ - D-glucuronide (MUG) and the chromophore 4-nitrophenyl- $\beta$-D-glucuronide (PNPG) were used for covalent modify the chitosan hydrogels, so obtain the detection of $\beta$-glucuronidase and consequently revealing the presence of $E$. Coli. The naked eye can observe the color variation from colorless to yellow. This chitosan-hydrogel-based sensor is promising for food packaging.

Chitosan-based nanocomposite biosensors are emerging tools for determining biomolecules such as cholesterol, glucose, urea, hydrogen peroxide [24].

A fiber optic sensor for measuring total cholesterol is developed by Mathews et al. [25]. The sensor is obtained by dip-coating a long period grating optical fiber with a thin layer of chitosan. The results showed the applicability of an LPG fiber optic-based system for the sensing of cholesterol. The wavelength and the intensity modulation are useful parameters for applying this sensor in real sample measurements.

Another interesting biosensor was developed by Du et al. [26]: they prepared a nanostructured chitosan-based electrode for salivary glucose sensing, build by using layerby-layer, self-assembly of single-walled carbon nanotubes, chitosan, gold nanoparticles and glucose oxidase on a screen-printed platinum electrode. Amperometric analyses are used for quantifying the glucose concentration in both synthetic solutions and saliva samples. Accuracy is verified by validation with a reference UV method.

An important, conclusive observation is that, when working with biopolymers, the main problem is the material's short lifetime. Even if good responses were obtained, the sensor must be calibrated before each analysis because the system's features may change as time passes.

\section{Synthetic Polymer-Based Sensors}

\subsection{Biocompatible Polymers}

The term "biocompatible polymers" refers to all those polymeric materials which present specific characteristics, such as very low toxicity, high stability in biological fluids, desired mechanical properties and surface chemistry, and biodegradability.

Thanks to their non-toxic nature, the application of these materials has increased exponentially in the last two decades, in many research fields, like the pharmaceutical industry, with the creation of drug carriers, and for medical applications such as biocontrol agents, biodegradable implants, and regenerative medicine [27].

The first example of biocompatible polymers is the naturally-derived ones, like cellulose, chitosan, and agarose (described in paragraph 2). Still, synthetic polymers are a no less good choice.

One example of synthetic biocompatible polymers is polyhydroxyalcanoates (PHAs), a biopolymer synthesized by bacteria as a carbon and energy storage $[28,29]$. They have emerged as a potential alternative to conventional plastics due to their biodegradability and sustainable production process, allowing reusing agriculture, food, dairy, or cosmetic industry waste as a main carbon substrate source. Poly-(R)-3-hydroxybutyrate and poly-3hydroxyvalerate are currently two of the main studied polymers in this class (Figure 7). 

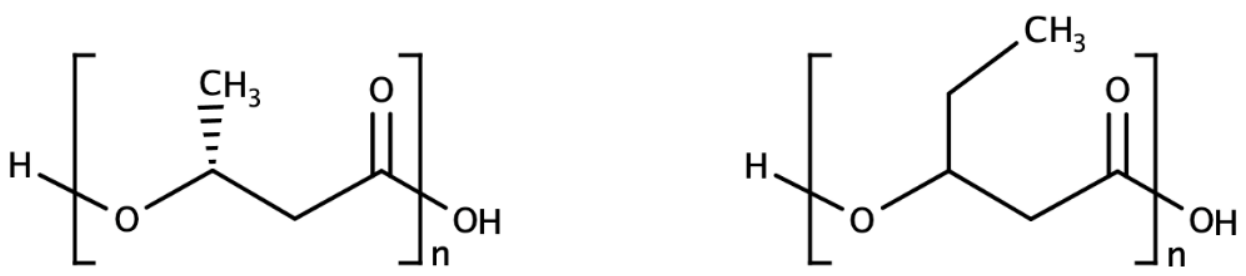

Figure 7. Chemical structures of poly-(R)-3-hydroxybutyrate (P3HB) and poly-3-hydroxyvalerate (PHV) (Adapted with permission from [29], available online, Wikimedia Commons, the free media repository).

The main characteristics of PHAs include thermo-plasticity, hydrophobicity, biodegradability, and their applications range from being used as coating materials to food packaging, agricultural sheets, and ink.

In this paragraph, we will present the application of biocompatible polymers in sensors.

The exploration of biopolymer materials is required to attain eco-friendliness and biocompatibility, limiting chemical sensors' application in personal health monitoring [30,31].

For example, polylactic-co-glycolic acid (PLGA, see Figure 8), a copolymer of polylactic acid and polyglycolic acid, is already approved by the FDA as biocompatible and biodegradable; it has been recently studied as a reactive polymer for humidity sensors.

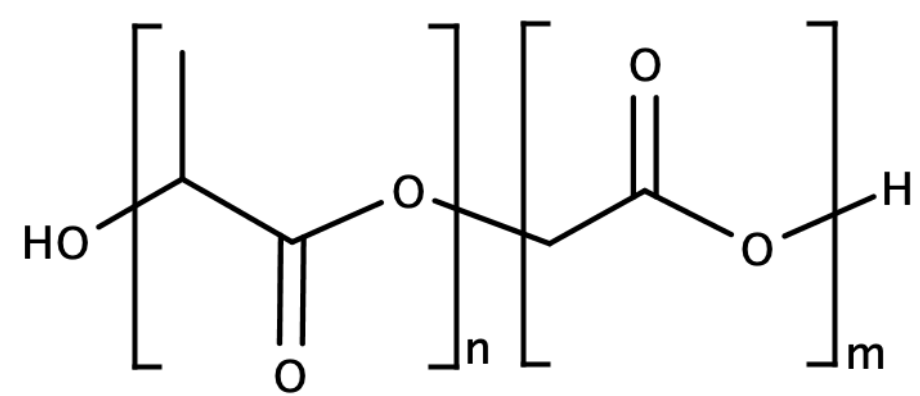

Figure 8. Chemical structure of polylactic-co-glycolic acid (Adapted with permission from [31], available online).

The time of this copolymer degradation depends on the ratio of polylactic acid/ polyglycolic acid: a higher percentage of glycolic acid makes the bio-copolymer more hydrophilic and incurs rapid biodegradation. PLGA with a 50:50 ratio of the two polymers presents optimal characteristics since the good hydrophilic properties and the crystalline structure supports its stability for humidity sensing.

Humidity is one of the fundamental environmental factors. Its measurement is highly required in various industrial fields, such as agriculture and food production and health and medical services. This type of device is prepared using all printed methods. The high-definition interdigitated electrode structure was printed on a flexible polyethylene terephthalate (PET) substrate, employing silver ink, by reverse offset printing set up; otherwise, PLGA ink was deposited using spin coating.

One particular application of the humidity sensor is human breathing monitoring, achieved since this sensor is eco-friendly and biocompatible. Lung epithelial cells were used to verify the PLGA biocompatibility and evaluate the respiration performance. The sensor was located under the volunteer's nose, and impedance measurements were registered. An increase in humidity ratio value increases the material's conductivity (decreasing resistance). Figure 9 shows the mechanism. 


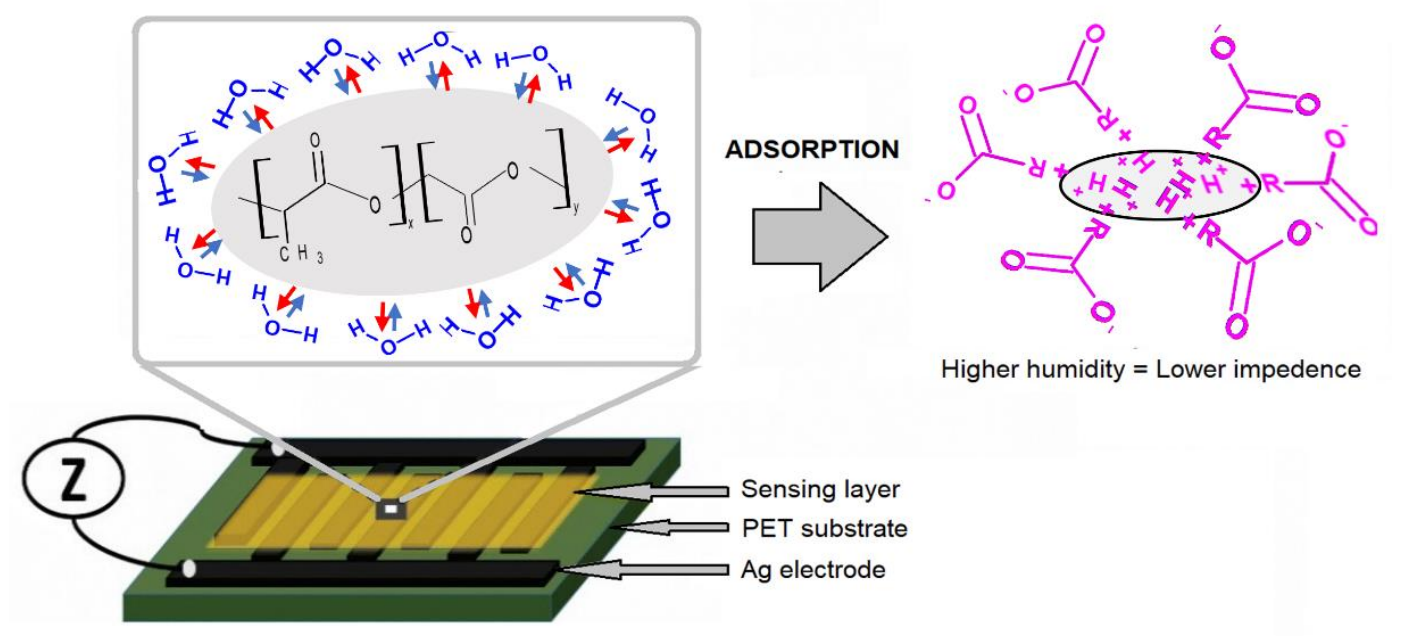

Figure 9. Humidity sensing mechanism. (Adapted with permission from [30], Copyright 2019, Springer Nature).

Another application of biopolymers as coating materials is their use for antibody support on gold surfaces [32] of plasmon resonance sensors to eliminate or minimize non-specific protein adsorption. This type of sensor is vastly employed as a medical tool for monitoring protein and biological markers, so stability in complex media like whole blood is highly required to monitor every disease or event that releases markers in any biological fluid, like myocardial infarction, using different antibodies on the surface.

Masson et al. [32] studied different biocompatible polymers as substitutes of carboxymethylated-dextran for antibody binding materials and reduced non-specific protein adsorption from serum to a level low enough to detect a specific antigen in the media. Non-specific binding of molecules to the SPR sensor's surface will cause a signal that will mask the analytes' one. This problem has prevented many useful applications of this tool.

The data obtained revealed that the two synthesized biocompatible polymers, polymethacrylic-acid-co-vinyl-acetate (PMAVA) and orthopyridyldisulfidepolyethylenglycol-N-Hydroxysuccinimide (OPSS-PEG-NHS, Figure 10, showed the best results in reducing non-specific protein binding to the surface of the SPR sensor gold surface. PMAVA reduced the phenomenon by $71 \%$, and OPPS-PEG-NHS reduced it by $67 \%$, both compared to carboxymethylated-dextran, which allowed the sensor to quantify a selected analyte up to a solid $\mathrm{ng} / \mathrm{mL}$ concentration.

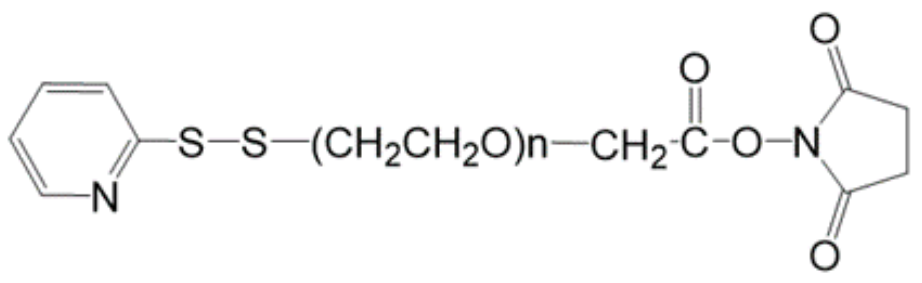

Figure 10. Molecular structure of OPSS-PEG-NHS. (Reproduced with permission from [33], available online).

Another way to achieve biocompatibility is to modify existing polymers, introducing particular groups that make the material more suitable for the desired biological applications. For example, nitric oxide-releasing/generating polymers can be used to develop implantable chemical sensors with enhanced biocompatibility [33,34].

The main problems with the development of reliable in vivo chemical sensor for realtime clinical monitoring of critically ill patients' parameters (electrolytes, glucose, etc.) are cell adhesion, thrombosis, and inflammation, that can produce inaccurate analytical results.

Nitric oxide (NO) is a known inhibitor of platelet activation and adhesion; it is a promoter of angiogenesis and a mediator of inflammatory response. Polymers, releasing 
or generating $\mathrm{NO}$ at their surface, exhibit greater thromboresistance in vivo when put in contact with flowing blood, as well as a reduced inflammatory response when placed subcutaneously. Thus, these polymers have the potential to improve the biocompatibility of implanted chemical sensors.

To date, the two most extensively investigated NO donors polymers for biomedical applications are S-nitrosothiols (RSNO) and N-diazeniumdiolates (so-called NONOates), dispersed into plasticized polyvinyl chloride (PVC) and polyurethane (PU) membranes. These membranes are typically used for preparing potentiometric ion-selective sensors. The NO-releasing mechanism from $\mathrm{N}$-diazeniumdiolates is proton-driven, and an example is depicted in Figure 11.

Polymer<smiles>CCCCNCCCCCCN(CCCC)C(=O)[O-]</smiles><smiles>CCCCNCCCCCCNCCCC</smiles>

\section{Blood}

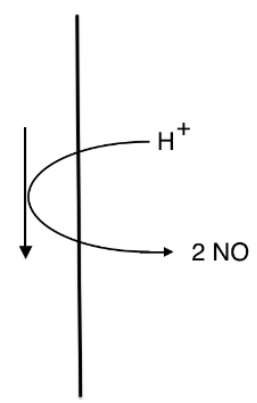

Figure 11. Mechanism of NO-release from dibutylhexyldiamine diazeniumdiolate (DBHD/ $\left.\mathrm{N}_{2} \mathrm{O}_{2}\right)$.

It is of fundamental importance that the period of NO release matches the device's implant lifetime. The molecule release rate is a crucial point, and it must be controlled to prevent the formation of any cytotoxic reaction product.

In conclusion, biocompatible polymers represent a valid material for sensor production due to their biocompatibility, biodegradability, and alternative eco-friendly production methods.

\subsection{EVOH Polymers}

EVOH is a copolymer of ethylene and vinyl alcohol commonly applied in food packaging and pharmaceutic industries thanks to its barrier properties against gases and humidity. The structure may not be obtained by copolymerizing ethylene and vinyl alcohol monomers (Figure 12) because the keto-enolic tautomeric equilibrium is shifted to the aldehydic form. For this reason, the most used synthetic pathway foresees ethylene and vinyl acetate as monomers with subsequent hydrolysis [35].

a)

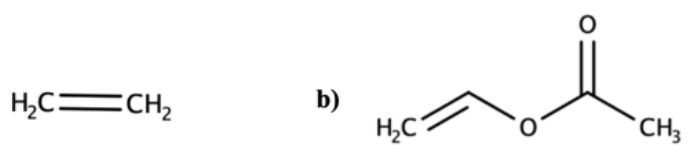

c)<smiles>CC(C)(C)CC(C)(C)CC(C)(C)C(O)C(C)(C)C</smiles>

Figure 12. (a) Ethylene; (b) Vinyl acetate; (c) ethylene vinyl-alcohol structures.

Commercially EVOH is sold in different percentages of ethylene $27 \%, 32 \%, 38 \%$, $44 \%$; the different percentage of monomers involves different barrier properties against gases and different solubility in organic solvents. For example, high ethylene rates in the structure would make the copolymer highly hygroscopic and, therefore, with low barrier 
properties forming hydrogels [36]. It is important to highlight that the tacticity and the new functions on the polymer's surface affect its solubility. The excellent mechanic properties and the ease of functionalization of the surface make $\mathrm{EVOH}$ an optimum candidate for sensors' development.

Cui et al. [37] developed a sensor for determining $\mathrm{Cu}^{2+}$ in aqueous solution using $\mathrm{EVOH}$ as a polymeric solid phase. EVOH nanofibers are modified with 4-aminobenzoic acid, forming EVOH-PABA and then with 1-pyrenecarboxyaldheyde (Py-CHO) (see the scheme of the process in Figure 13).

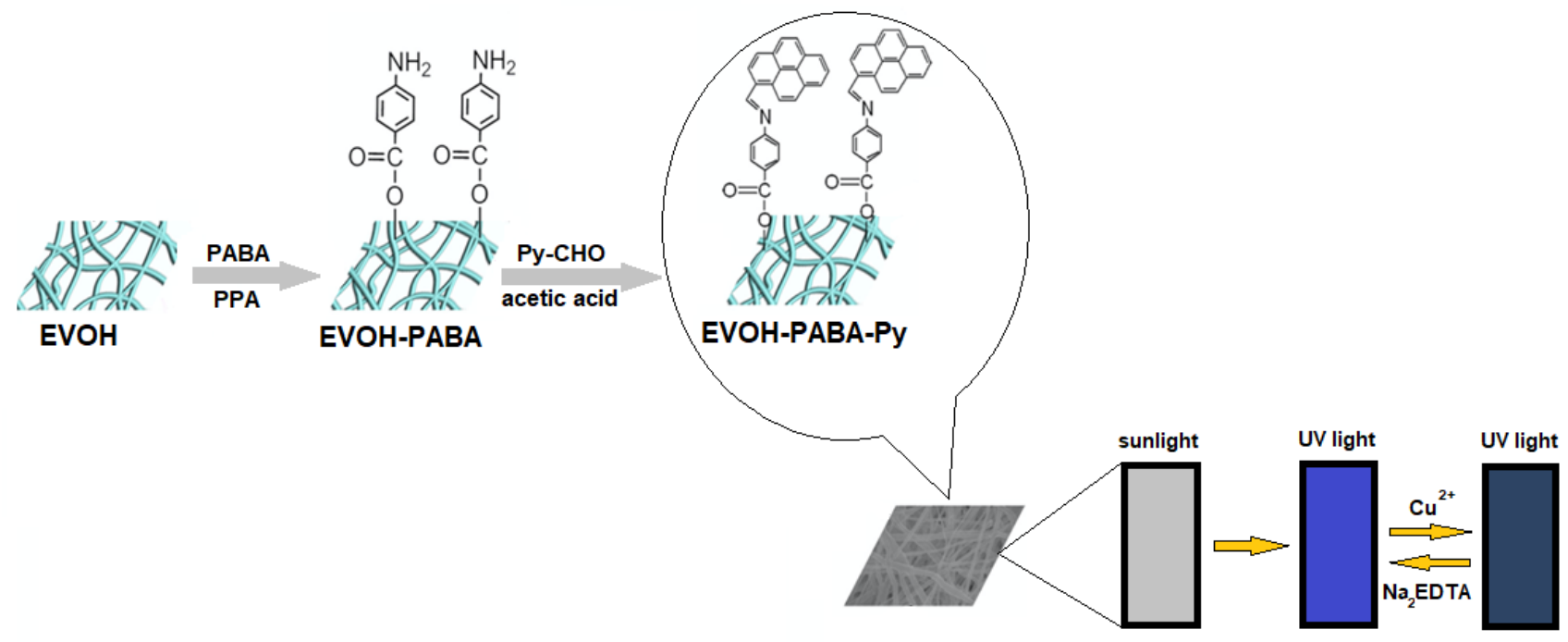

Figure 13. General scheme of the synthesis and the application of the sensor for $\mathrm{Cu}^{2+}$.

The principle of this sensing method is the luminescence quenching by $\mathrm{Cu}^{2+}$. The nitrogen probably coordinates the metal cation; thus, an electron transfer from the pyrene to $\mathrm{Cu}^{2+}$ takes place, favoring a non-radiative relaxation. Measurements are purchased in the presence of $\mathrm{Fe}^{3+}$ and $\mathrm{Hg}^{2+}$ in the solution phase. These cations gave a low quenching of luminescence. For this reason, the proposed method may be considered selective against $\mathrm{Cu}^{2+}$ in solution [37].

Magnaghi et al. [38] developed a very interesting innovative polymeric optode based on EVOH copolymer for high-protein food spoilage. In this study, EVOH was functionalized with different dyes (see Figure 14), changing color at different $\mathrm{pHs.}$

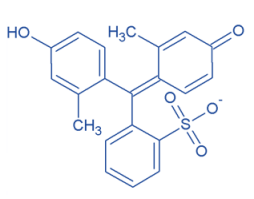

$m$-cresol purple

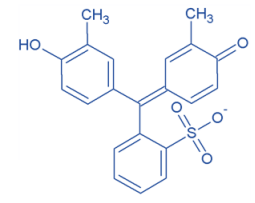

o-cresol red

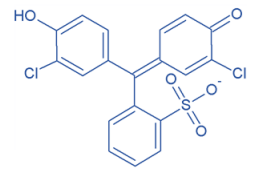

Chloro-phenol red

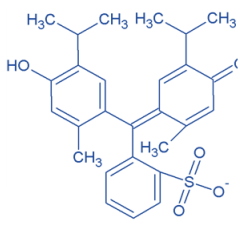

Thymol blue

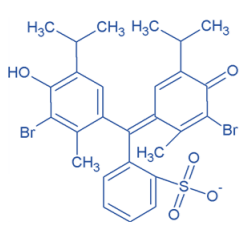

Bromothymol blue

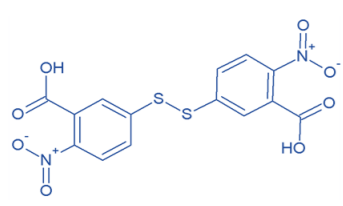

Elmann's reagent

Figure 14. Structure of the dyes used for preparing EVOH-based optode for evaluating high-protein food spoilage (Adapted with permission from [38], Copyright 2020, ACS). 
Sensors change color depending on the ambient $\mathrm{pH}$ in which they are introduced. RGB data were collected and analyzed thanks to principal component analysis.

Similarly, Alberti et al. [39] developed a sensor for Fe(III) where EVOH was used as a solid phase. The copolymer was functionalized with deferoxamine mesylate (DFO) and 3,4-hydroxypyridinone ligand (KC18) (Figure 15). These ligands can form colored complexes with Fe(III).

(A)<smiles>CC(=O)N(O)CCCCCNC(=O)CCC(=O)N(O)CCCCCNC(=O)CCC(=O)N(O)CCCCCN</smiles>

(B)

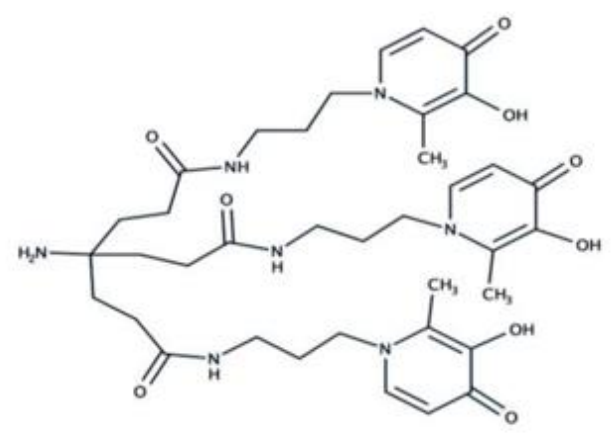

Figure 15. (A) Deferoxamine (B) 3,4-hydroxipyridinone structures. (Adapted with permission from [39], open access Creative Common CC licenced 4.0, MDPI).

López-Carballo et al. [40] developed a chromatic sensor for $\mathrm{O}_{2}$ based on blue methylene, glycerol, $\mathrm{TiO}_{2}$, and $\mathrm{EVOH}$. The presence of oxygen must be prevented inside food packaging in order to preserve the content. The research group developed a sensing solid phase where $\mathrm{TiO}_{2}$, glycerol, and blue methylene are mixed inside an EVOH matrix. The obtained material was used to form films and coatings. The sensing mechanism is reported in the following image (Figure 16).
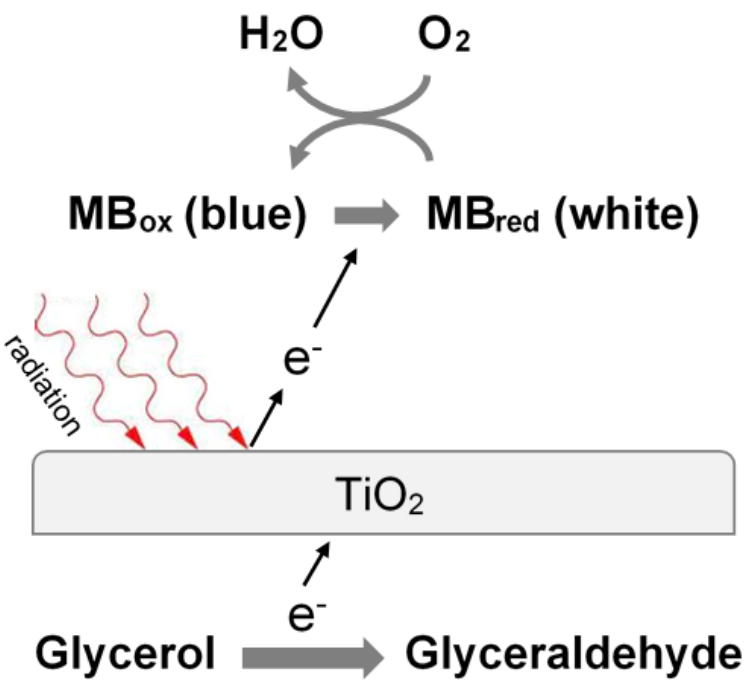

Figure 16. Mechanism scheme of the sensor for $\mathrm{O}_{2}$ detection. (Adapted with permission from [39], open access Creative Common CC licenced 4.0, MDPI).

As evident, the presence of $\mathrm{O}_{2}$ causes the color change of the sensor from blue to white.

Mahato and Adhikari [41] developed an e-tongue to monitor drinking water quality. It is based on functionalized polymer membrane electrodes. The study aims to compare 
different drinking waters according to the mineral salts content, and data were treated thanks to the chemometric principal component analysis (PCA) tool. The developed sensors can detect the change of the surface polarizability by interacting with the analytes ions with the polymer's surface. In this study, $\mathrm{EVOH}$ was phosphorylated in order to optimize swelling properties. This copolymer's surface has polar functional groups that interact with the drinking water's dissolved minerals. The sensor's mechanism is directly related to the Gouy-Chapman theory of the electrical double layer.

The double-layer at the metallic electrode's surface is different from that of the electrode surface after modification with the $\mathrm{EVOH}$ polymer. In the presence of an ionic solution, an interaction between ions and the charged surface occurred. This interaction contributed to the electric potential: the potential varied consequently to the changes in the solution's minerals content.

In summary, EVOH can be efficiently used for developing chemical sensors, particularly as support for obtaining extrudable material, which, in principle, is convenient for practical applications thanks to its ability to be dissolved in hydro-alcoholic mixtures and applied on flexible substrates by coating or printing procedures.

\subsection{Acrylic Polymers}

Acrylic polymers pertain to the class of typical polymeric materials. They can be used in sensors thanks to their versatility since several sensory functionalities can be chemically bound to their structure, conferring to the obtained materials different properties. The most important acrylic polymers used for this aim are prepared with esters of methacrylic or acrylic acid, acrylamide derivatives, and copolymers. Several functionalities can be anchored to the acrylic moiety to design polymer-based sensors [42].

Garcia et al. developed several fluorescent and colorimetric sensors based on acrylic polymers for different analytes [43-48]. The strategy consists of preparing a thin film polymer by radical polymerization of three monomer units: 1-vinyl-2-pyrrolidone (VP) as the hydrophilic unit, methylmethacrylate (MMA) as the hydrophobic monomer, and a sensory unit, i.e., a monomer with a reactive side moiety properly designed. For example, in the most recent paper, ninhydrin-based colorimetric polymer for monitoring chronic human wounds' evolution was presented (see Figure 17) [48].

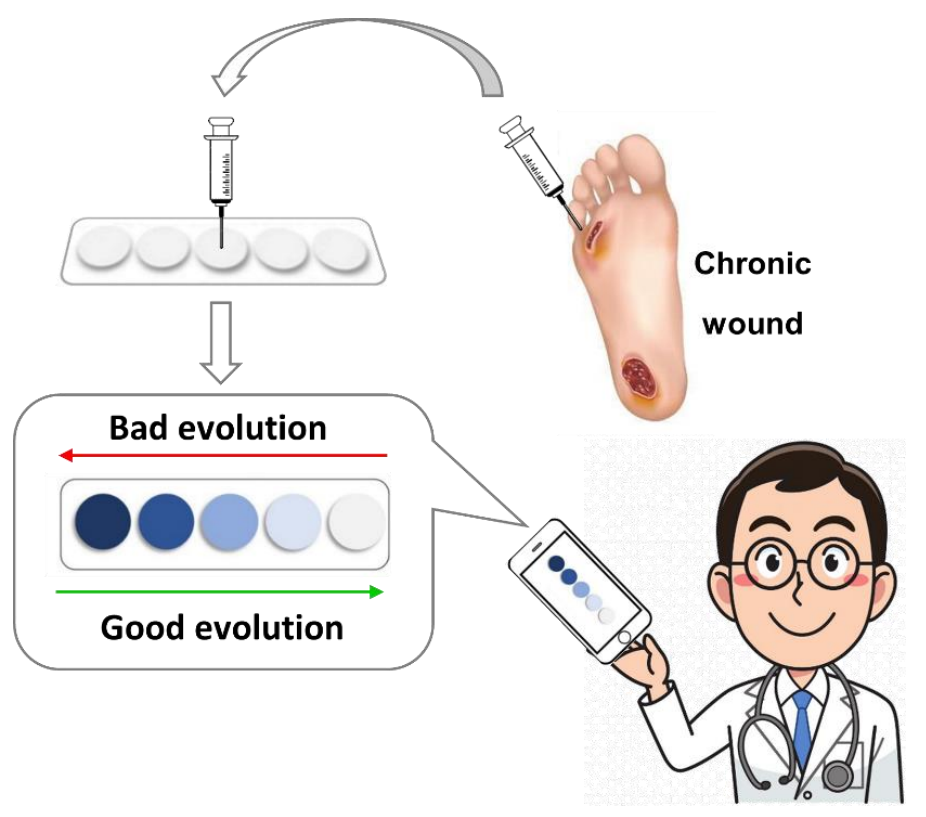

Figure 17. Scheme of the ninhydrin-based sensor for monitoring chronic human wounds' evolution with a smartphone's assistance. 
The kit consists of a colorimetric polymer film able to change its color after contact with amino acids. The kit lets quantify a total amino acid concentration by analyzing the sensory film's color parameters (RGB) obtained from a smartphone's photos. With this simple equipment, the amino acid concentration of chronic human wounds of 34 patients was determined. The author also demonstrated a correlation between the amino acid concentration associated with protease activity and the evolution of the wound's diagnoses. This device can help diagnose chronic human injuries, providing an analytical method not affected by subjective estimation.

A pH polyacrylate-based sensor is developed by Chowdhury et al. [49]. In this study, polyacrylic acid (PAA) is synthesized by free-radical polymerization in aqueous solutions under ultrasound. The employment of ultra-sound allows a robust and green polymerization. PAA is then used as a capping agent to synthesize AgNPs without any other reducing agents or UV/gamma radiations. The Ag-PA sol obtained is applied for sensing $\mathrm{pH}$ by the naked eye. This work is an example of a low-cost $\mathrm{pH}$ sensor based on a colorimetric smart polymer of practical utility.

Another interesting study reports the development of Sc(III) polyacrylic-based optoelectronic humidity sensor [50]. Nanostructured scandium polyacrylate is deposited on flat borosilicate substrates to study the sorption/desorption of humidity at room temperature. Figure 18 shows the humidity sensing mechanism; in particular, chemosorption and less bending of light are verified in a less humid region. Conversely, physisorption and greater bending of light are observed in a high humid region.
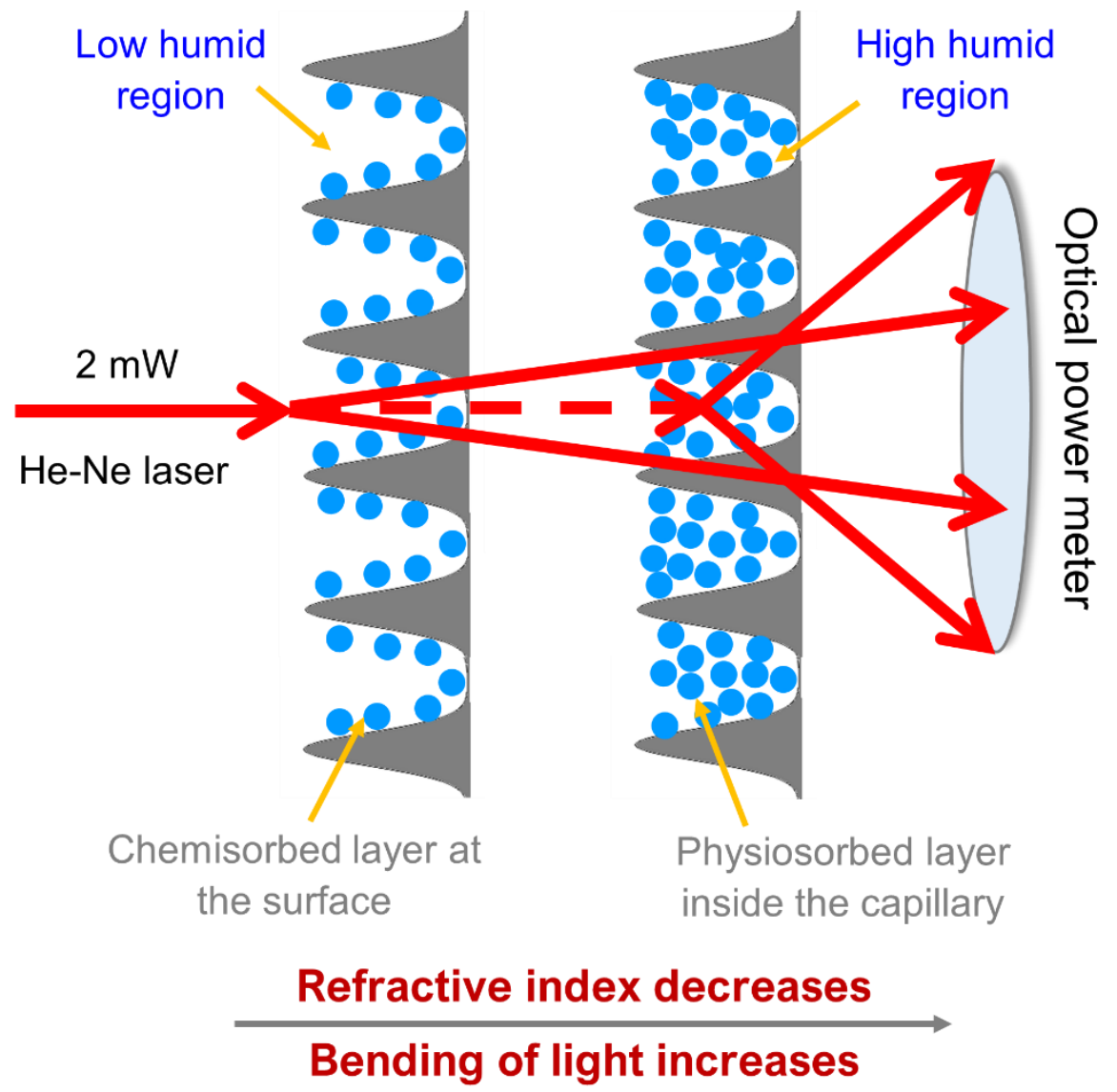

Figure 18. Humidity sensor's sensing mechanism. The picture shows, for less humid regions, chemisorption and less bending of light. For high humid regions, physisorption and greater bending of light were observed. (Adapted with permission from [50], Copyright 1969, IEEE). 
The sensor showed a sensitivity value of $2.1 \mu \mathrm{W} / \% \mathrm{RH}$ with $89 \%$ of reproducibility; response and recovery times of the sensor are at 25 and $155 \mathrm{~s}$, respectively. It is promising as a very efficient humidity sensing device.

\subsection{Molecular Imprinting Polymers (MIPs)}

Molecular imprinting consists of the formation of synthetic receptors in a polymer by a template-induced method. Specific recognition sites obtained using the molecular imprinting process possess excellent properties such as high affinity, specificity, robustness, and economical production, making them interesting alternatives to natural receptors. Enhancements in nanotechnology and polymer science have contributed to the advancement of molecularly imprinted polymer (MIP) sensors' performance.

Molecular recognition is essential in biological processes. At present, it is the focal point of several pieces of research due to its importance in techniques such as sensing, separations, and catalysis. Natural systems produce antibodies against a range of antigens; however, the use of such receptors in chemical processes encounters numerous problems, such as sensitivity to environmental conditions and high cost. Modern sensor research aims to develop synthetic receptors able to mimic the natural antibody-antigen interaction with similar sensitivity and specificity.

The molecular imprinting process consists of the formation, in a polymer, of molecular recognition sites obtained by performing the synthesis in the presence of the target analyte that acts as a template. Connections between the template and functional monomers are retained in their arrangement during the polymerization and stabilized by the polymer's crosslinking. The resulting MIP is consequently able to recognize the target analyte in the template-derived sites selectively [51,52].

Figure 19 shows a scheme of the molecularly imprinted polymer preparation [53].
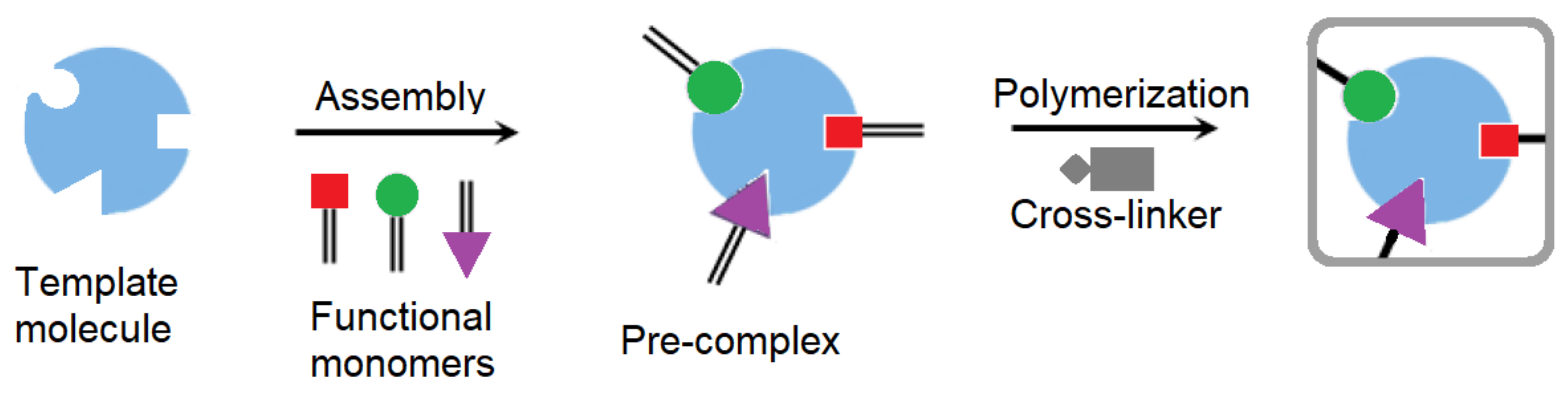

Pre-complex
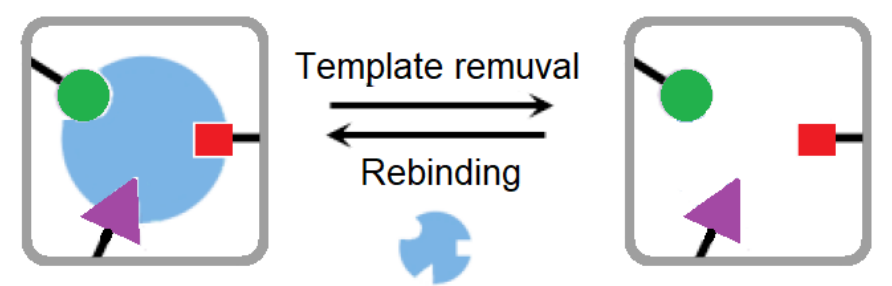
Molecularly
Imprinted
Polymer

Figure 19. Scheme of a MIP preparation. (Adapted with permission from [53], open access Creative Common CC licenced 4.0, MDPI).

Molecular imprinting polymers can be prepared for several templates such as enzymes, proteins, bacteria, viruses, metal ions, toxins, etc. Thanks to their perfect recognition sites, they are promising materials, especially in sensor devices.

MIPs-based sensors are capable and cost-effective devices for biomolecules. They can be applied in different techniques, including electrochemical, optical, and piezoelectric sensing [53]. 
Electrochemical sensors are based on the interaction between the analyte and a receptor on an electrode's surface. These devices employ different electroanalytical techniques. Commonly measured properties are the potential at zero current (potentiometry), the current vs. potential variations (voltammetry), the current at a fixed potential (amperometry); otherwise, conductivity, and capacitance or impedance variations.

A current trend in electrochemical MIPs-based sensors is the employment of microparticles and nanoparticles (NPs) or nanostructured coatings.

For example, in an interesting work [54], a voltammetric sensor for theophylline is proposed, using sol-gel immobilized molecularly imprinted polymer particles. Theophylline is a methylxanthine alkaloid of the purine family. It can be found in cocoa beans, teas, some beverages, and plant material; its structure is analog to caffeine and theobromine. For over seventy years, it has been used to treat asthma and chronic pulmonary disease, thanks to its low cost and large availability. In this paper, a theophylline-imprinted polymer incorporated in a voltammetric sensor is described. Using the sol-gel technique, microspherical and macroporous MIP particles are immobilized together with graphite (the conducting medium) on a carbon electrode's surface. Differential pulse voltammetry is applied as a voltammetric technique to quantify theophylline at concentrations low to $1 \mu \mathrm{M}$, similar or more down to the values reported for other electrochemical methods.

Another unusual but promising work [55] proposed a novel duplex MIP-based sensor for metronidazole detection. Metronidazole (MNZ) is a synthetic antiprotozoal drug firstly introduced in 1960 for medical practice. In particular, it is an antibiotic used to treat a wide range of infections. It works by blocking the growth of some bacteria and parasites. In this study, the sensor is based on a novel duplex molecularly imprinted polymer (DMIP), deposited on a carbon paste electrode (CPE). The DMIP film is comprised of two layers: one of a conductive polymer and the second of an imprinted polysiloxane. Initially, a conductive film of poly(anilinomethyltriethoxysilane) is electrodeposited on the surface of CPE. The polymer's triethoxysilyl groups are hydrolyzed with 3-aminopropyltriethoxysilane, the functional monomer, tetraethyl orthosilicate, the crosslinker, in the presence of the template MNZ, forming a MIPS film over the conductive layer. The so obtained DMIP modified CPE is used for MNZ determination in pharmaceutical and biological samples applying differential pulse voltammetry (DPV). The sensor showed high sensitivity, selectivity, and pretty good accuracy.

Over the recent years, there is an evident increase of MIP-based sensors applied to biological samples. One example reported a cocaine potentiometric MIP nanoparticlebased sensor [56]. Cocaine is one of the most popular recreational drugs. Its abuse causes dangerous side-effects such as organ damage, anxiety, and cardiac arrest, in addition to economic and social impacts. Consequently, it is really important to develop sensitive and easy-to-use methods for cocaine detection, particularly for medical and forensic purposes. The potentiometric sensor developed is based on molecularly imprinted polymer nanoparticles (nanoMIPs) obtained by a solid-phase imprinting technique. In particular, nanoMIPs prepared with acrylamide as a functional monomer demonstrated the highest yield and affinity to cocaine, so they were selected for sensor development. For designing the ion-selective membrane of the electrode, the nanoparticles were incorporated within a PVC matrix. The sensor can determine cocaine in blood serum samples in the range of 1 $\mathrm{nM}-1 \mathrm{mM}$ concentrations.

In a recent research [57], a temperature-sensitive electrochemical MIP-based sensor for the detection of bovine serum albumin (BSA) was proposed. Namely, the biosensor is based on a thermo-responsive hydrogel film obtained by free radical polymerization on a glassy carbon electrode's surface. The BSA sensing is due to a reversible structural change of the MIP after applying an external temperature stimulus. In particular, sorption and desorption processes have been observed by cyclic voltammetry $(\mathrm{CV})$ and electrochemical impedance spectroscopy (EIS) of the electrochemical probe $\left[\mathrm{Fe}(\mathrm{CN})_{6}\right]^{3-/ 4-}$. This BSA sensor showed high selectivity, stability, with good recovery and reproducibility. 
Moreover, MIP-based sensors are compliant with disposable plastic fiber optics and screen-printed electrodes (SPEs).

About these topics, Pesavento and co-workers recently proposed a MIP-based electrochemical sensor for 2-furaldehyde (2-FAL) detection in beverages [58]. The detection bases on the reduction of 2-FAL sorbed on the MIP layer in contact with the working electrode of a screen-printed cell. The peak current signal (ip) measured by square wave voltammetry (SWV) is directly proportional to the 2-FAL concentration. The good sensitivity and so the detection limit (LOD) of about $2.5 \mu \mathrm{M}$, was successfully improved by applying the design of experiments (DoE) approach for selecting the best SWV conditions.

Furthermore, a completely different transduction principle was exploited to study the binding properties of the same MIP for 2-FAL, i.e., a platform based on the optical phenomenon of the SPR [59]. For preparing the MIP-SPR sensor, a D-shaped plastic optical fiber (POF) with a planar surface is prepared by erasing the cladding and partially the core. Over this POF was deposited a multilayer of MIP. The platform is suitable for investigating the binding properties of the MIP since the signal, namely the variation of the resonance wavelength $(\lambda$ shift), occurs in response to the bind between the 2-FAL and the MIP sites. Indeed, it is due to the refractive index variation of the MIP layer. Also, the possibility of performing single drop measurements is a good aspect for real sample analysis. 2-FAL determination in fermented beverages is becoming a crucial task, mostly for the effects of furans on the flavor of food and their toxicity.

About MIPs-based optical sensors, we can distinguish two categories: MIP-affinity sensors and optoelectronic MIP sensors.

In the first case, the devices can detect analytes with optical properties (for example, absorbance, fluorescence, refractive index. The binding analyte/MIP's site produces an optical change, such as an increase of absorbance at a defined wavelength or a fluorescence quenching, or a refractive index variation. A typical example of this category of optical MIP sensing is that just above described [59].

For the second category sensors, the mechanism bases on the presence of monomers with optical properties, able to sense changes in their surroundings and respond to the analyte's presence. An example is an optical fiber fluorescent chemical sensor for cocaine developed by Wren and co-workers [60]. A rationally designed fluorophore was synthesized, and then it was introduced into a molecularly imprinted polymer, so obtaining an optical fiber fluorescent probe. The change of the emitted fluorescence is related to the concentration of cocaine in the sample. A good limit of detection of about $1 \mu \mathrm{M}$ makes this sensor promising and builds on develops in a new direction by defining a rapid and low-cost method. It may be a help for forensic analysis of drugs.

Concluding, we have described some MIPs-based electrochemical and optical sensors highlighting the applications to real samples. MIPs went further to be a simple proof of concept. The challenge now is to increase the robustness, scale up the production, and find a suitable market.

\subsection{Conducting Polymers}

Conducting polymers are characterized by their capacity to delocalize electrons thanks to the $\pi$ structure of the polymer chain. In 1972 MacDiarmid, Shirakawa and Heeger showed for the first time that polyacetylene could turn into a conducting polymer when doped with $\mathrm{Br}_{2}$ and $\mathrm{I}_{2}$ [61]. This innovation was rewarded with the Nobel prize for chemistry in 2000. Conducting polymers has several advantages; for example, they show metallic and semiconducting properties by doping. The materials can combine electronic and plastic properties. They can be modified, solubilized in organic solvents, and printed with low-cost procedures. Obviously, there are also some disadvantages; for example, they do not have long-term stability. Thanks to their behaviors, the application fields are various: supercapacitor, nano-coatings, catalysis, biomedical, and sensors [62]. The most used conducting polymers are polyacetylene (PA), polyaniline (PANI), polypyrrole (PPy), 
polythiophene (PTH), poly(para-phenylene) (PPP), poly(phenylenevinylene) (PPV), and polyfuran (PF) (see Figure 20).

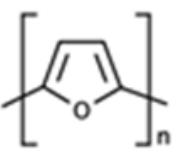

PF

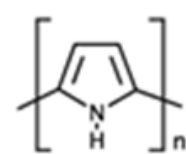

PPy

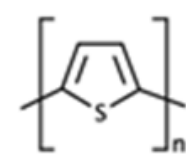

PTH

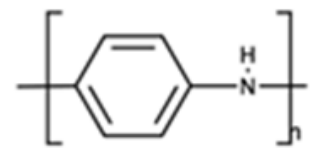

PA

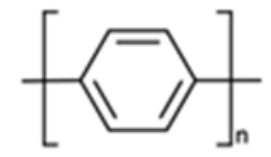

PPP

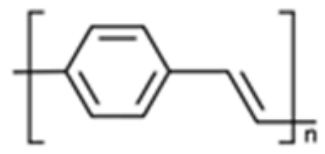

PPV

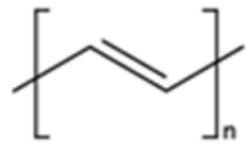

PA

Figure 20. Schematic structures of polyfuran, polypyrrole, polythiophene, polyaniline, poly(para-phenylene), poly(phenylenevinylene), and polyacetylene.

In this section, we discuss the application of conducting polymers in sensors. Thanks to their redox behavior, conducting polymers are used for electrochemical sensing to detect gases. To understand how the sensor works, we have to focus on the different kinds of polymer dopings. Doping may be $p$-type or $n$-type; both configurations may turn the polymer from a semiconducting material to a conducting. In $p$-type, electrons flow from the HOMO of the polymer chain to the LUMO* of the electron with-drawing doping agent. This transition generates holes in the polymer, which will become electron-poor. In $n$-type doping, electrons flow from the HOMO of the doping agent to the LUMO* of the polymer, which will become electron-rich. The polymer chain may also be oxidized or reduced with electrochemical techniques by imposing the appropriate potential.

When polyacetylene is not doped, it behaves like a semiconductor material with a bandgap of $3.16 \mathrm{eV}$; actually, when $p$-type doped, the polymer chain is oxidized and twists the configuration from benzoid to quinoid. The polymer doping generates a new band structure with a bandgap of $1.4 \mathrm{eV}$, turning the polymer from a semiconductor to a conductor. The instrumental setups may be several, for example, amperometric, transistor and diode sensor, piezoelectric crystal sensor, optic sensor, but the most widely used is the chemoresistor because it gives rapid responses and LOD is under $10 \mathrm{ppm}$ [63].

When the oxidized polymer ( $p$-type) met a reducing agent $\left(\mathrm{CO}, \mathrm{NH}_{3}, \mathrm{CH}_{4}, \mathrm{H}_{2}, \mathrm{H}_{2} \mathrm{~S}\right.$, acetone, ethanol), the resistivity increases; vice versa if the surface of the polymer reacts with an oxidating agent $\left(\mathrm{NO}_{\mathrm{x}}, \mathrm{CO}_{2}, \mathrm{SO}_{2}, \mathrm{O}_{2}, \mathrm{O}_{3}\right)$ the resistivity decreases [62,64].

One of the most studied conducting polymer-based gas sensors is for $\mathrm{NH}_{3}$. Korent et al. [65] described in 2021 a simple and economical sensor for $\mathrm{NH}_{3}$ based on the functionalization of a screen printed electrode (SPE) with polyaniline (PANI). In this work, the SPE is modified with polyaniline electrochemically polymerized in the presence of $\mathrm{HCl}$. The collected signal is given from the redox reaction between the oxidized polymer substrate $\left(\mathrm{PANIH}^{+}\right)$and the gas; this exchange of electrons generates electric flow:

$$
\mathrm{PANIH}^{+}+\mathrm{NH}_{3} \rightleftarrows \mathrm{PANI}+\mathrm{NH}_{4}^{+}
$$

The redox activity of conducting polymers is often used in electronic noses. Electronic noses are arrays able to simulate the olfactive human system, which can detect and identify an odor. All information is sent to the brain, which must attribute every signal to a compound. Like the brain, the electronic nose must attribute every signal to a compound contained in a mixture of molecules. This data analysis is possible thanks to pattern recognition which is an algorithm able to split the data coming from the sensor; an example is the principal component analysis (PCA). Before electronic noses, the only method able to detect and identify a mixture of gases was GC/MS; this method is very expensive, needs 
qualified personnel and the response time was very long. Sensors made with conducting polymers are chipper than GC/MS. The assembling of the device can be automated, for example, with the 3D printing technology, and the response time is in the range of few seconds $[66,67]$.

Conducting polymers are also used for biosensors. Forzani et al. [68] studied an electrochemical sensor for glucose using glucose oxidase (GOx). The array is made of polyaniline nano junctions where the monomer is electropolymerized in the presence of poly(acrylic acid). Then the glucose oxidase is fixed on the surface of the polymer. GOx promotes glucose oxidation to gluconolactone, and the enzyme is reduced to $\mathrm{GOx}\left(\mathrm{FADH}_{2}\right)$. The reduced enzyme reacts with the oxygen present in the solution forming GOxFAD and $\mathrm{H}_{2} \mathrm{O}_{2}$. In the last step, the peroxide oxidizes the conducting polymer [68]:

$$
\begin{gathered}
\text { glucose }+\mathrm{GOx}(\mathrm{FAD}) \rightarrow \text { gluconolactone }+\mathrm{GOx}\left(\mathrm{FADH}_{2}\right) \\
\mathrm{GOx}\left(\mathrm{FADH}_{2}\right)+\mathrm{O}_{2} \rightarrow \mathrm{GOx}(\mathrm{FAD})+\mathrm{H}_{2} \mathrm{O}_{2} \\
\mathrm{PANI}_{\mathrm{red}}+\mathrm{H}_{2} \mathrm{O}_{2} \rightarrow \mathrm{H}_{2} \mathrm{O}+\mathrm{PANI}_{\mathrm{ox}}
\end{gathered}
$$

The oxidized polymer shows a decrease in resistivity when increasing the glucose concentration. The sensor's response time is around $1 \mathrm{~s}$. This very fast response is possible thanks to the polymer nano junctions' nanostructure and is necessary for real-time determinations.

An interesting application of conducting polymers was studied by Swager et al. [69]. They assembled a sensor for $\mathrm{Na}^{+}$using modified polythiophene as conducting polymer. In the first part of this work, the polythiophene chain is modified with a crown ether able to complex the alkaline metals. When the modified polymer does not bound the cations, the polythiophene backbone maintains the planarity, and the charge is delocalized in the $\pi$ system. When the crown ether complexes $\mathrm{Na}^{+}$, the structure is twisted, this distortion from the planarity decreases the conjugation and so the conductivity (Figure 21).
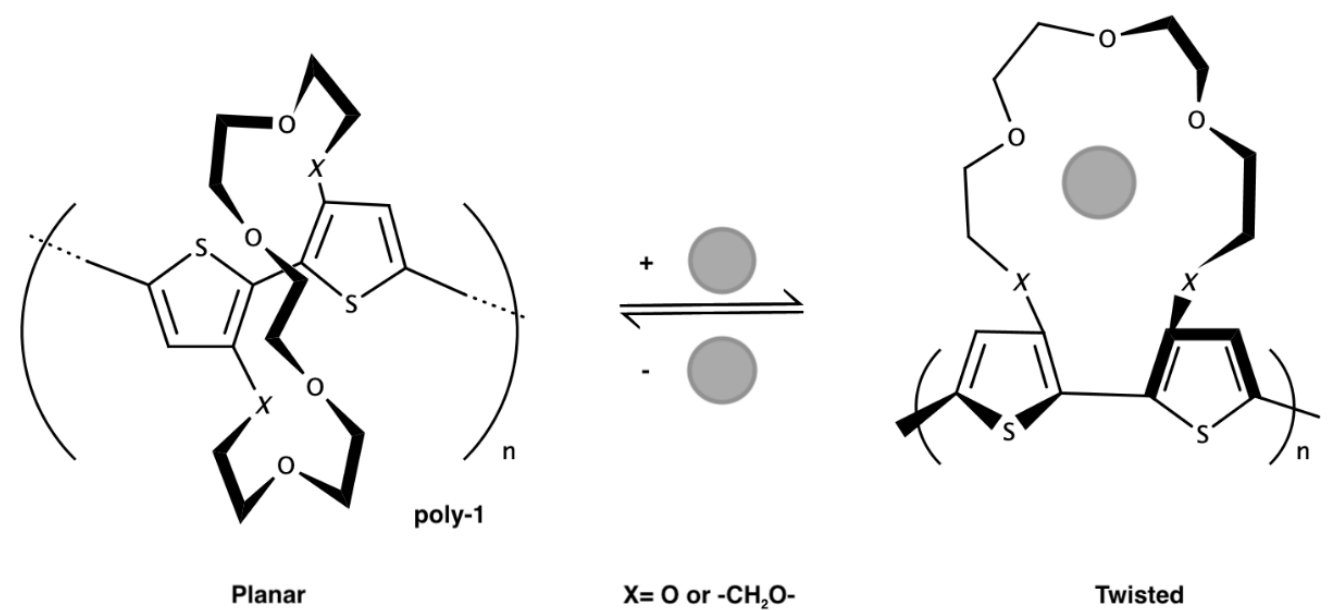

Plana $\mathrm{X}=\mathrm{O}$ or $-\mathrm{CH}_{2} \mathrm{O}-$

Twisted

Figure 21. Crown ether modified polythiophene for sensing of alkaline metal cations. (Adapted with permission from [69], Copyright 1995, ACS).

This kind of sensor is based on the variation of the conductivity by varying the concentration of the alkaline metals in solution.

In the second part of this research, the polythiophene chain is modified with a calixarene, able to emit in fluorescence, and with an electron donor spacer, which can decrease the oxidation potential of the polymer. If the polymer chain is able to delocalize the charge, the calixarene can emit in fluorescence (Figure 22). 


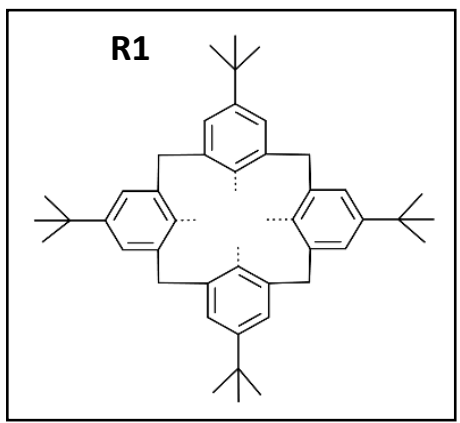

R1

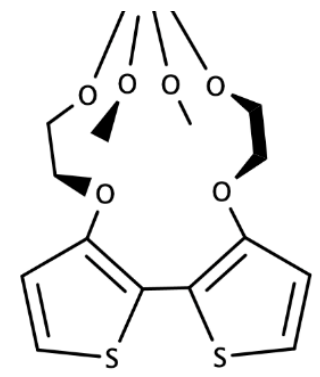

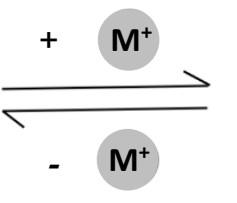

$\mathrm{M}^{+}=\mathrm{K}^{+}, \mathrm{Na}^{+}$or $\mathrm{Li}^{+}$
R1

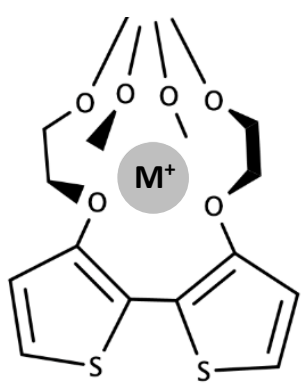

Figure 22. Calixarene modified polythiophene for sensing of alkaline metal cations.

A variation of fluorescence was noted when the concentration of $\mathrm{Na}^{+}$changed in the solution; besides, the emitted band was very sharp and red-shifted in the presence of $\mathrm{Na}^{+}$. These two characteristics of the emitted band are related to the presence of $\mathrm{Na}^{+}$inside of the macrocycle. The alkaline metal cation contributes to modify the bond length and promotes the planarization of the polymer chain. When the polymer chain is flat, the conductivity increases. From the electrochemical studies, the obtained data are different compared to those from the fluorescence measurements. If the polymer is electrochemically oxidized in the presence of $\mathrm{Na}^{+}$, the conductivity decreases. This effect is probably due to the inductive influence of oxygens in the macrocycle, which is stronger than planarization $[69,70]$.

In summary, conducting polymers are widely used in all kinds of sensors thanks to their tunable electronical behaviors, ease of polymerization, and low-cost production.

\subsection{Polymer Nanocomposites}

Polymer nanocomposites (PNCs) are obtained by combining a continuous polymeric phase and nanoparticles as a discontinuous phase. Numerous pros in mechanical, optical, and electric properties have attracted scientists worldwide. PNCs can be synthesized in different forms, suitable for developing chemical and biological sensors.

Nanostructured polymers greatly impact biological and technology areas, especially in drug delivery, catalysis, and sensor applications [71].

High electrical conductivity, large surface area, and fast electron rate make PNCs excellent candidates for electrochemical sensor development.

These electrochemical devices are based on three different categories of PNCs: those obtained by the combination of conductive polymers and inorganic nanomaterials, the other formed by conductive polymers and graphene, and those obtained by conductive polymers and carbon nanotubes [72].

In the first case, the insertion of metal nanoparticles in the PNC matrice improved electrocatalytic electrode detection leading to several applications. For example, zinc oxide nanoparticles intercalated into polypyrrole (ZnO-PPy) PNCs are employed to develop a xanthine sensor. The enzyme xanthine oxidase is immobilized onto the nanocomposite film through physisorption. The sensor gave optimum response within $5 \mathrm{~s}$ (at pH 7.0 and $35^{\circ} \mathrm{C}$ ), and linearity from 0.8 to $40 \mu \mathrm{M}$, with a detection limit of $0.8 \mu \mathrm{M}$ [73]. 
A voltammetric sensor based on polyaniline-gold nanoparticles deposited on a glassy carbon electrode is used for the simultaneous epinephrine and uric acid determination [74]. Cyclic voltammetry, electrochemical impedance spectroscopy, and atomic force microscopy are applied to characterize the sensor. The electrochemical behavior of both analytes was investigated in phosphate buffer solutions at $\mathrm{pH}$ 6.6. The method showed sensitivity, high precision, and good reproducibility.

The recent advances in wearable devices and nanotechnology have made great efforts in polymer nanocomposite-based wearable sensors for healthcare and medical diagnosis, prosthetics, professional sports, robotic systems, and visual realities. Wearable devices can be linked to clothes or taped on the human skin by adhesive or elastic straps for monitoring physical signals and motions [75]. The recent progress in materials science and nanotechnology significantly contributed to developing high-performance wearable sensors with high flexibility, stretchability, and sensitivity. For obtaining devices with these properties, the selection of suitable functional materials is fundamental. Several conductive nanomaterials were employed to develop polymer nanocomposite-based sensors, including carbon nanotubes, graphene, Ag or Au nanowires, and conductive polymers. Even though they provide good electrical conductivity, these materials often show inadequate mechanical properties such as poor stretchability and flexibility. These two properties can be obtained by developing composite materials consisting of electrically conductive fillers and an elastomeric matrix. The conductive fillers provide the sensing mechanism, and the elastomeric matrix provides the required mechanical properties [75].

In this field, an interesting work [76] reported piezoresistive sensors developed for strain-sensors using a triblock copolymer (styrene-butadiene-styrene) thermoplastic elastomer as a polymeric matrix, reinforced with carbon nanofillers as the conductive material. These sensors were obtained by extrusion or spray printing techniques that allow scaling-up and incorporation into new devices.

The materials were integrated into a glove with the readout and wireless communication system (see Figure 23); their ability to monitor finger movements was demonstrated.

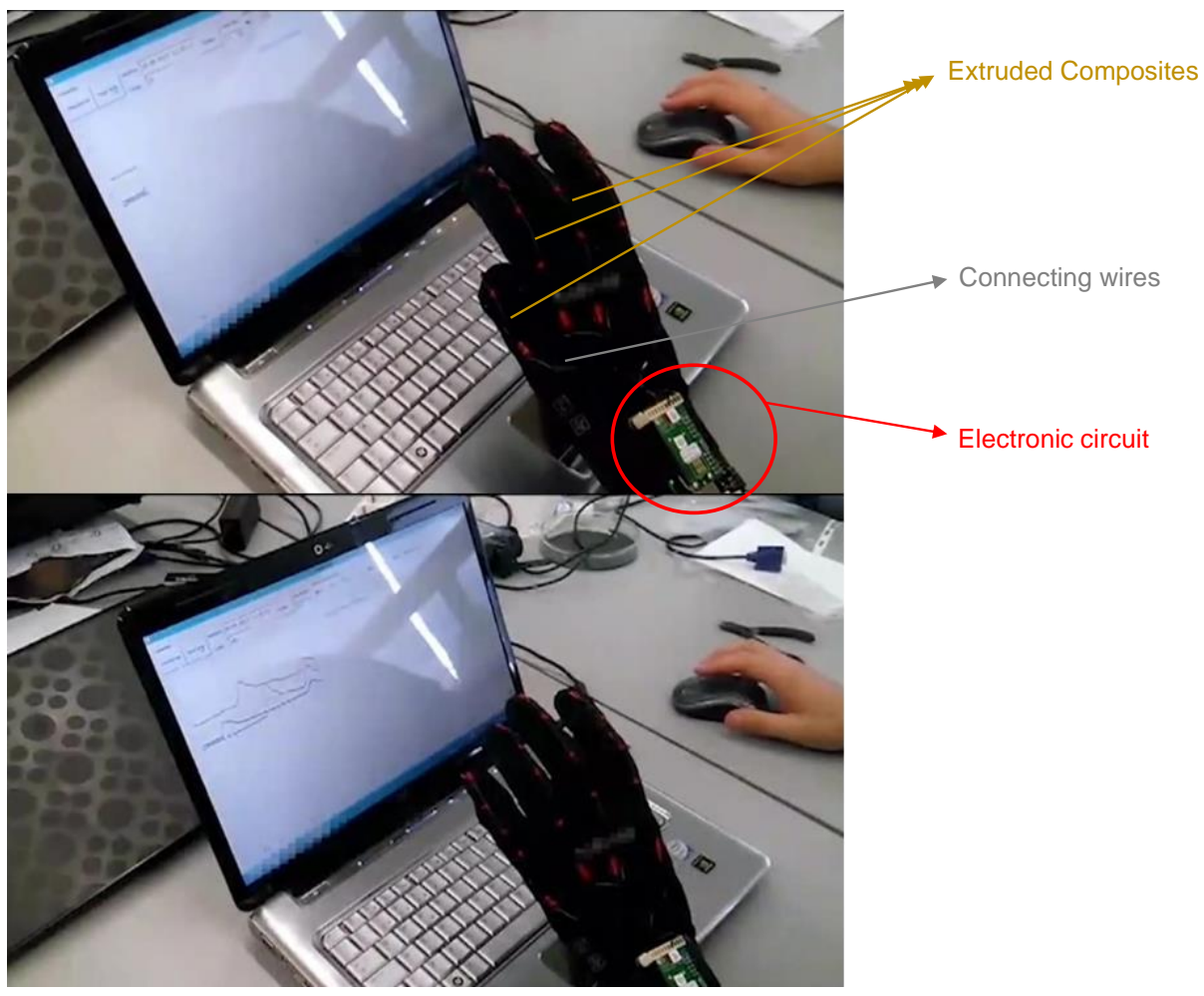

Figure 23. Piezoresistive sensors integrated into the glove. 
Graphene is an emergent two-dimensional carbon material. It can be an excellent candidate for strain sensors because of its smart electrical, optical and mechanical properties. Chun et al. [77] developed graphene (single-layer graphene and graphene flake thin film) based sensors on stretchable polydimethylsiloxane substrate, able to detect infinitesimal strains (as low as $0.1 \%$ ) with distinct output signals. This sensor can monitor various human body motions such as stretching, bending, and torsion.

The effective combination of various nanoscale materials with conductive polymers opens new opportunities for applying PNCs in electrochemical sensing and biosensing platforms with high-level performances.

\subsection{Polymer Inclusion Membranes}

Polymer inclusion membranes (PIMs), introduced about 50 years ago, are polymerbased liquid membranes used as the sensing part of ion-selective electrodes and optical sensors (optodes). Recently, PIMs are also applied in sample preparation and pre-concentration, passive sampling and can be incorporated into online and automated instruments.

A PIM is composed of a liquid phase and a polymeric support, usually poly(vinyl chloride), cellulose triacetate, or poly(vinylidene fluoride-co-hexafluoropropylene).

The skeleton of the membrane is the polymeric phase since it provides mechanical strength. The liquid phase contains an extractant (carrier) responsible for binding the analyte by ion-pair formation or complexation. Some carriers already present plasticizing characteristics; however, an additional plasticizer or modifier is incorporated during the membrane preparation for improving the flexibility or making the analyte more soluble in the liquid phase.

PIMs are commonly obtained by dissolving all components in a small volume of a volatile solvent (dichloromethane or tetrahydrofuran) and casting. The solvent was left to evaporate slowly until a homogeneous and transparent PIM is obtained on the cast surface that can be flat or cylindrical. For example, the membrane can be cast onto an electrode body's tip to prepare an ion-selective electrode. Flat-sheet PIMs can be used to develop optical sensors by inserting a chromophore into the membrane composition [78,79].

In a recent study [80], a label-free potentiometric biosensor for Salmonella typhimurium (ST) is described. It is assembled in a homemade pipette-tip electrode. A gold nanoparticle polymer inclusion membrane (AuNPs-PIM) was applied both as a sensing platform and for immobilizing the antibody. The proposed sensor shows potential for on-site food control thanks to a simple experimental procedure and potentiometric instrumentation portability. A working range of 1.3-13 $\times 10^{6}$ cells $\mathrm{mL}^{-1}$ and a LOD of 6 cells $\mathrm{mL}^{-1}$, comparable with other electrochemical label-free immunosensors for ST, demonstrated the good performance of the developed platform. The proposed method can be applied to a different bacteria-antibody couple, simply changing the specific antibody and optimizing the AuNP-PIM.

A disposable optode is developed for $\mathrm{Zn}(\mathrm{II})$ determination [81]. It is obtained by immobilization of a dye, the 2-acetylpyridine benzoyl hydrazone (2-APBH), in a polymer inclusion membrane stuck on the surface of a strip of polyester. An experimental factorial design is applied for optimizing the membrane composition to obtain a material of good appearance and suitable physical and optical properties. The optimal membrane is formed by $2.5 \mathrm{~g}$ PVC, $4 \mathrm{~mL}$ of tributyl phosphate, and $40 \mathrm{mg}$ of $2-\mathrm{APBH}$. The optode showed a linear range from 0.03 (i.e., the LOD) to $1 \mathrm{mg} \mathrm{L}^{-1}$, of $\mathrm{Zn}(\mathrm{II})$, and it responds in about $30 \mathrm{~min}$ when immersed in aqueous solutions at $\mathrm{pH}=6$. The sensitivity to $\mathrm{Zn}$ (II) compared to that for other common cations is excellent. The device is applied for $\mathrm{Zn}$ (II) determination in certified water (reference material), spiked tap water, mineral drink, food integrators, and foot health care products, providing reliable results.

This paragraph highlighted the growing interest in PIMs in chemical sensing. The future challenge is the production of miniaturized PIMs-based devices with high sensitivity and suitable for environmental, biological, and clinical analysis [78]. 


\section{Conclusions}

Several sensors are based on polymers with well-defined characteristics. Polymers can be directly involved in the sensing mechanism, or specific receptors can be immobilized on them. Table 1 summarizes the natural and synthetic polymers often used in sensors. The current trend in polymer-based technologies for sensing applications is reviewed here. The advantages of employing polymers for sensors are not restricted to lightweight, softness, biocompatibility, flexibility, stretchability, ease functionalization, cost-effective production, and long lifetime. Even if significant attempts were made to obtain better performances for the current sensors, modest signs of progress were perceived in these devices' marketing. Interdisciplinary collaboration among chemists, engineers, and computer scientists should be the right direction to implement large-scale development and production to overcome these difficulties (see outlook Figure 24).

Table 1. Name, origin and applications of the natural and synthetic polymers used for preparing the sensors described in this review.

\begin{tabular}{|c|c|c|c|}
\hline Name & Origin & Applications & Ref. \\
\hline Cellulose & Plant & Paper, colorimetric sensor, textile fiber & {$[4,82]$} \\
\hline Hemicellulose & Plant & Stabilizer in cosmetic and pharmaceutic, fuel & {$[83,84]$} \\
\hline Glucomannan & Plant & Alimentar field & [85] \\
\hline Agarose & Plant & Matrix for the analysis of biological molecules & [86] \\
\hline Starch & Plant & Alimentar field & [87] \\
\hline Pectin & Plant & Alimentar field & [88] \\
\hline Inulin & Plant & Alimentar field & [89] \\
\hline Acacia gum & Plant & Alimentar field & {$[90]$} \\
\hline Chitin & Animal & Medical and alimentar field & {$[91,92]$} \\
\hline Chitosan & Animal & Alimentar field & [92] \\
\hline Alginate & Animal & Solid phase in chemistry & [93] \\
\hline Polyhydroxyalcanoates & Bacteria & Agriculture, food packaging and cosmetics & [28] \\
\hline $\begin{array}{l}\text { Polylactic-co-glycolic acid } \\
\text { (PLGA) }\end{array}$ & Synthetic & Humidity sensors & [31] \\
\hline $\begin{array}{l}\text { Polyethylene terephtalate } \\
\text { (PET) }\end{array}$ & Synthetic & Packaging, flexible substrate for sensors & [94] \\
\hline $\begin{array}{l}\text { Ethylene vinyl alcohol } \\
\text { (EVOH) }\end{array}$ & Synthetic & Packaging, flexible substrate for sensors & [35] \\
\hline Polyvinyl chloride (PVC) & Synthetic & Industrial field, construction, chemical matrix for sensors & {$[34,95]$} \\
\hline Polyfuran (PF) & Synthetic & Electronics & [96] \\
\hline Polypyrrole (PPy) & Synthetic & Electronics and chemical sensors & [73] \\
\hline Polythiophene (PTH) & Synthetic & $\begin{array}{l}\text { Antistatic coatings, windows and mirrors coatings, } \\
\text { chemical sensors }\end{array}$ & {$[69,97]$} \\
\hline Polyaniline (PA) & Synthetic & Acid base sensor, supercapacitor, biosensor & [68] \\
\hline Poly(para-phenylene) (PPP) & Synthetic & Electronics & [62] \\
\hline $\begin{array}{l}\text { Poly(phenylenevinylene) } \\
\text { (PPV) }\end{array}$ & Synthetic & Electronis & [62] \\
\hline Polyacetilene (PA) & Synthetic & Electronics and chemical sensors & [98] \\
\hline Polyaniline (PANI) & Synthetic & $\begin{array}{c}\text { Conductive polymer-based sensors, printed circuit } \\
\text { manufacturing, }\end{array}$ & {$[65,99]$} \\
\hline
\end{tabular}




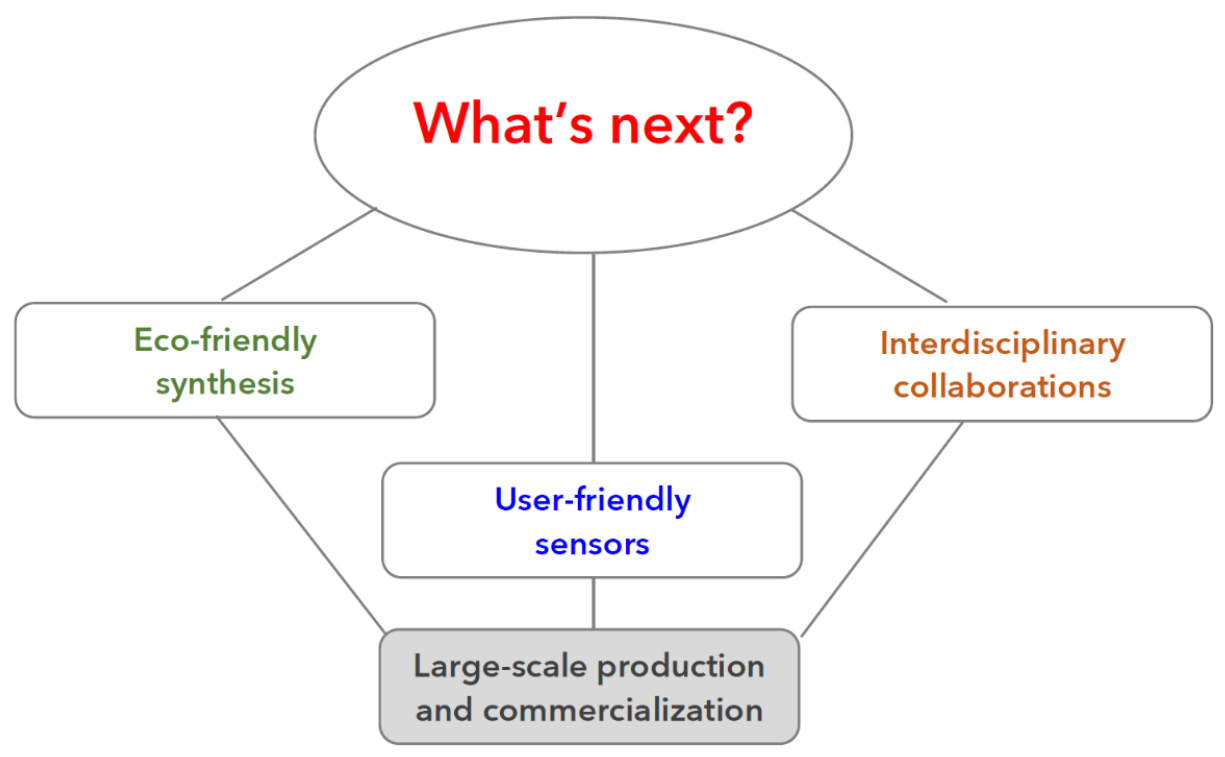

Figure 24. Outlook figure about the new perspectives in polymer-based sensors.

Author Contributions: Conceptualization, G.A., C.Z.; writing-original draft preparation, G.A., C.Z., V.L.; writing-review and editing G.A., C.Z., V.L., R.B., L.R.M. All authors have read and agreed to the published version of the manuscript.

Funding: This research received no external funding.

Institutional Review Board Statement: Not applicable.

Informed Consent Statement: Not applicable.

Data Availability Statement: Not applicable.

Conflicts of Interest: The authors declare no conflict of interest.

\section{References}

1. Cichosz, S.; Masek, A.; Zaborski, M. Polymer-based sensors: A review. Polym. Test. 2018, 67, 342-348. [CrossRef]

2. Carvalho, W.S.P.; Wei, M.; Ikpo, N.; Gao, Y.; Serpe, M.J. Polymer-Based Technologies for Sensing Applications. Anal. Chem. 2018, 90, 459-479. [CrossRef]

3. Kulkarni, V.S.; Butte, K.D.; Rathod, S.S. Natural Polymers-A Comprehensive Review. Int. Res. J. Pharm. Appl. Sci. 2012, 3, 1597-1613.

4. Qiu, X.; Hu, S. "Smart" Materials Based on Cellulose: A Review of the Preparations, Properties, and Applications. Materials 2013, 6, 738-781. [CrossRef]

5. Alberti, G.; Quattrini, F.; Colleoni, R.; Nurchi, V.M.; Biesuz, R. Deferoxamine-paper for iron(III) and vanadium(V) sensing. Chem. Pap. 2015, 69, 1024-1032. [CrossRef]

6. Takagai, Y.; Yamaguchi, H.; Kubota, T.; Igarashi, S. Selective visual determination of vanadium(V) ion in highly acidic solution using desferrioxamine B immobilization cellulose. Chem. Lett. 2007, 36, 136-137. [CrossRef]

7. Alberti, G.; Nurchi, V.M.; Magnaghi, L.R.; Biesuz, R. A portable, disposable, and low-cost optode for sulphide and thiol detection. Anal. Meth 2019, 11, 4464-4470. [CrossRef]

8. Biesuz, R.; Nurchi, V.M.; Magnaghi, L.R.; Alberti, G. Inexpensive Alizarin Red S-based optical device for the simultaneous detection of Fe(III) and Al(III). Microchem. J. 2019, 149, 104036. [CrossRef]

9. Alberti, G.; Zanoni, C.; Magnaghi, L.R.; Biesuz, R. Low-cost, disposable colourimetric sensors for metal ions detection. J. Anal. Sci. Technol. 2020, 11, 30. [CrossRef]

10. Magnaghi, L.R.; Capone, F.; Zanoni, C.; Alberti, G.; Quadrelli, P.; Biesuz, R. Colorimetric sensor array for monitoring, modelling and comparing spoilage processes of different meat and fish foods. Foods 2020, 9, 684. [CrossRef]

11. Guo, W.; He, H.; Zhu, H.; Hou, X.; Chen, X.; Zhou, S.; Wang, S.; Huang, L.; Lin, J. Preparation and properties of a biomass cellulose-based colorimetric sensor for Ag+ and $\mathrm{Cu}^{2+}$. Ind. Crops Prod. 2019, 137, 410-418. [CrossRef]

12. Golmohammadi, H.; Morales-Narváez, E.; Naghdi, T.; Merkoçi, A. Nanocellulose in Sensing and Biosensing. Chem. Mater. 2017, 29, 5426-5446. [CrossRef]

13. Chauhan, P.; Hadad, C.; López, A.H.; Silvestrini, S.; La Parola, V.; Frison, E.; Maggini, M.; Prato, M.; Carofiglio, T. A nanocellulosedye conjugate for multi-format optical pH-sensing. Chem. Commun. 2014, 50, 9493-9496. [CrossRef] [PubMed] 
14. Carofiglio, T.; Fregonese, C.; Mohr, G.J.; Rastrelli, F.; Tonellato, U. Optical sensor arrays: One-pot, multiparallel synthesis, and cellulose immobilization ofpHand metal ion sensitive azo-dyes. Tetrahedron 2006, 62, 1502-1507. [CrossRef]

15. Petri, D.F.; Donegá, J.; Benassi, A.M.; Bocangel, J.A. Preliminary study on chitosan modified glass ionomer restoratives. Dent. Mater. 2007, 23, 1004-1010. [CrossRef]

16. Cruz, J.; Kawasaki, M.; Gorski, W. Electrode coatings based on chitosan scaffolds. Anal. Chem. 2000, 72, 680-686. [CrossRef] [PubMed]

17. Xin, Y.; Guanghan, L.; Xiaogang, W.; Tong, Z. Studies on Electrochemical Behavior of Bromideat a Chitosan-Modified Glassy Carbon Electrode. Electroanalysis 2001, 13, 923-926. [CrossRef]

18. Darder, M.; Colilla, M.; Ruiz-Hitzky, E. Chitosan-clay nanocomposites: Application as electrochemical sensors. Appl. Clay Sci. 2005, 28, 199-208. [CrossRef]

19. Kurniasih, D.; Atikah, A.; Sulistyarti, H. The Coated-Wire Ion Selective Electrode (CWISE) of ChromateUsing PVC-Membrane Based on Chitosan as A Carrier. J. Pure App. Chem. Res. 2012, 1, 33-40. [CrossRef]

20. Magalhães, J.M.C.S.; Machado, A.A.S.C. Urea potentiometric biosensor based on urease immobilized on chitosan membranes. Talanta 1998, 47, 183-191. [CrossRef]

21. Wang, H.; Qian, J.; Ding, F. Emerging Chitosan-Based Films for Food Packaging Applications. J. Agric. Food Chem. 2018, 66, 395-413. [CrossRef]

22. Cavallo, J.A.; Strumia, M.C.; Gomez, C.G. Preparation of a milk spoilage indicator adsorbed to a modified polypropylene film as an attempt to build a smart packaging. J. Food Eng. 2014, 136, 48-55. [CrossRef]

23. Sadat Ebrahimi, M.M.; Voss, Y.; Schonherr, H. Rapid detection of Escherichia coli via enzymatically triggered reactions in self-reporting chitosan hydrogels. ACS Appl. Mater. Interfaces 2015, 7, 20190-20199. [CrossRef]

24. Muthusankar, E.; Ragupathy, D. Chitosan Based Nanocomposite Biosensors: A Recent Review. Sens. Lett. 2018, 16, 81-91. [CrossRef]

25. Mathews, C.B.; Libish, T.M.; Kaushalkumar, B.; Vivek, V.; Prabhu, R.; Radhakrishnan, P. A fiber optic biosensor for the detection of cholesterol levels based on chitosan-coated long period grating. Optoelectron. Lett. 2016, 12, 23. [CrossRef]

26. Du, Y.; Zhang, W.; Wang, M.L. Sensing of salivary glucose using nanostructured biosensors. Biosensors 2016, 6, 10. [CrossRef] [PubMed]

27. Ko, H.F.; Sfeir, C.; Kumta, P.N. Novel synthesis strategies for natural polymer and composite biomaterials as potential scaffolds for tissue engineering. Philos. Trans. A Math Phys. Eng. Sci. 2010, 368, 1981-1997. [CrossRef]

28. Vecchiato, V.; Basnett, P. Insights into the Economical Production of Polyhydroxyalkanoates. Polym. Sci. Peer Rev. J. 2020, 1. Available online: https:/ / crimsonpublishers.com/psprj/pdf/PSPRJ.000511.pdf (accessed on 4 December 2020).

29. Available online: https://en.wikipedia.org/wiki/Polyhydroxyalkanoates (accessed on 30 March 2021).

30. Soomro, A.M.; Jabbar, F.; Ali, M.; Lee, J.-W.; Mun, S.W.; Choi, K.H. All-range flexible and biocompatible humidity sensor based on poly lactic glycolic acid (PLGA) and its application in human breathing for wearale health monitoring. J. Mater. Sci. Mater. Electron. 2019, 30, 9455-9465. [CrossRef]

31. Available online: https:/ / polylactide.com/polylactic-co-glycolic-acid/ (accessed on 26 March 2021).

32. Masson, J.F.; Battaglia, T.M.; Davidson, M.J.; Kim, Y.C.; Prakash, A.M.; Beaudoin, S.; Booksh, K.S. Biocompatible polymers for antibody supportt on gold surfaces. Talanta 2005, 67, 918-925. [CrossRef]

33. Available online: https:/ / www.nanosoftpolymers.com/product/opss-peg-nhs/ (accessed on 23 March 2021).

34. Wu, Y.; Meyerhoff, M.E. Nitric oxide-releasing/generating polymers for the development of implantable chemical sensors with enhanced biocompatibility. Talanta 2008, 75, 642-650. [CrossRef]

35. Paradinha, M.M.; Dias, F.T.G.; Wanke, C.H.; de Lima Novello, J.C.; Tondo, E.C.; De Nardi Martins, J.; Bianchi, O. Preparation and characterization of the ethylene-vinyl acetate copolymer partially hydrolyzed assisted by microwave radiation. J. Appl. Polym. Sci. 2017, 134, 44558. [CrossRef]

36. Kim, D.; Kwon, H.; Seo, J. EVOH nanocomposite films with enhanced barrier properties under high humidity conditions. Polym. Compos. 2014, 35, 644-654. [CrossRef]

37. Cui, X.; Li, T.; Li, J.; An, Y.; An, L.; Zhang, X.; Zhang, Z. A highly selective and reversible turn-off fluorescent chemosensor for $\mathrm{Cu}^{2+}$ based on electrospun nanofibrous membrane modified with pyrenecarboxaldehyde. Spectrochim. Acta A Mol. Biomol. Spectrosc. 2019, 207, 173-182. [CrossRef] [PubMed]

38. Magnaghi, L.R.; Alberti, G.; Milanese, C.; Quadrelli, P.; Biesuz, R. Naked-Eye Food Freshness Detection: Innovative Polymeric Optode for High-Protein Food Spoilage Monitoring. ACS Food Sci. Technol. 2021, 1, 165-175. [CrossRef]

39. Alberti, G.; Zanoni, C.; Magnaghi, L.R.; Santos, M.A.; Nurchi, V.M.; Biesuz, R. DFO@EVOH and 3,4-HP@EVOH: Towards New Polymeric Sorbents for Iron(III). Chemosensors 2020, 8, 111. [CrossRef]

40. López-Carballo, G.; Muriel-Galet, V.; Hernández-Muñoz, P.; Gavara, R. Chromatic Sensor to Determine Oxygen Presence for Applications in Intelligent Packaging. Sensors 2019, 19, 4684. [CrossRef]

41. Mahato, M.; Adhikari, B. Monitoring of drinking water quality: A preliminary approach by an electronic tongue based on functionalized polymer membrane electrodes. Anal. Meth. 2017, 9, 6019-6031. [CrossRef]

42. Reglero Ruiz, J.A.; Sanjuán, A.M.; Vallejos, S.; García, F.C.; García, J.M. Smart Polymers in Micro and Nano Sensory Devices. Chemosensors 2018, 6, 12. [CrossRef] 
43. Vallejos, S.; Muñoz, A.; García, F.C.; Colleoni, R.; Biesuz, R.; Alberti, G.; García, J.M. Colorimetric detection, quantification and extraction of $\mathrm{Fe}(\mathrm{III})$ inwater by acrylic polymers with pendant Kojic acid motifs. Sens. Actuators B Chem. 2016, 233, 120-126. [CrossRef]

44. Trigo-López, M.; Muñoz, A.; Ibeas, S.; Serna, F.; García, F.C.; García, J.M. Colorimetric detection and determination of Fe(III), $\mathrm{Co}(\mathrm{II}), \mathrm{Cu}(\mathrm{II}), \mathrm{Sn}(\mathrm{II})$ in aqueous media by acrylic polymers with pendant terpyridine motifs. Sens. Actuators B Chem. 2016, 8 , 118-126. [CrossRef]

45. Bustamante, S.E.; Vallejos, S.; Pascual-Portal, B.S.; Muñoz, A.; Mendia, A.; Rivas, B.L.; Garcia, F.C.; Garcia, J.M. Polymer films containing chemically anchored diazonium salts with long-term stability as colorimetric sensors. J. Hazard. Mater. 2019, 365, 725-732. [CrossRef] [PubMed]

46. Guembe-Garcia, M.; Vallejos, S.; Carreira-Barral, I.; Ibeas, S.; Garcia, F.C.; Santaolalla-Garcia, V.; Moradillo-Renuncio, N.; Garcia, J.M. Zn(II) detection in biological samples with a smart sensory polymer. React. Funct. Polym. 2020, 154, 104685. [CrossRef]

47. Gonzalez-Ceballos, L.; Cavia, M.D.M.; Fernández-Muiño, M.A.; Osés, S.M.; Sancho, M.T.; Ibeas, S.; García, F.C.; García, J.M.; Vallejos, S. A simple one-pot determination of both total phenolic content and antioxidant activity of honey by polymer chemosensors. Food Chem. 2021, 342, 128300. [CrossRef] [PubMed]

48. Guembe-García, M.; Santaolalla-García, V.; Moradillo-Renuncio, N.; Ibeas, S.; Reglero, J.A.; García, F.C.; Pacheco, J.; Casado, S.; García, J.M.; Vallejos, S. Monitoring of the evolution of human chronic wounds using a ninhydrin-based sensory polymer and a smartphone. Sens. Actuators B Chem. 2021, 335, 129688. [CrossRef]

49. Chowdhury, P.; Hazra, A.; Mondal, M.K.; Roy, B.; Roy, D.; Bayen, S.P.; Pal, S. Facile synthesis of polyacrylate directed silver nanoparticles for $\mathrm{pH}$ sensing through naked eye. J. Macromol. Sci. A 2019, 56, 773-780. [CrossRef]

50. Sikarwar, S.; Kumar, A.; Yadav, B.C.; Iskakovna, D.G.; Danilovna, G.N. Nanostructured Spherical-Shaped Sc(III) Polyacrylate for Monitoring the Moisture Level. IEEE Sens. J. 2018, 18, 4384-4391. [CrossRef]

51. Ahmad, O.S.; Bedwell, T.S.; Esen, C.; Garcia-Cruz, A.; Piletsky, S.A. Molecularly Imprinted Polymers in Electrochemical and Optical Sensors. Trends Biotechnol. 2019, 37, 294-309. [CrossRef] [PubMed]

52. BelBruno, J.J. Molecularly Imprinted Polymers. Chem. Rev. 2019, 119, 94-119. [CrossRef]

53. Saylan, Y.; Akgönüllü, S.; Yavuz, H.; Ünal, S.; Denizli, A. Molecularly Imprinted Polymer Based Sensors for Medical Applications. Sensors 2019, 19, 1279. [CrossRef]

54. Bates, F.; del Valle, M. Voltammetric sensor for theophylline using sol-gel immobilized molecularly imprintedpolymer particles. Microchim. Acta 2015, 82, 933-942. [CrossRef]

55. Xiao, N.; Deng, J.; Cheng, J.; Ju, S.; Zhao, H.; Xie, J.; Qian, D.; He, J. Carbon paste electrode modified with duplex molecularly imprinted polymer hybrid film for metronidazole detection. Biosens. Bioelectron. 2016, 81, 54-60. [CrossRef]

56. Smolinska-Kempisty, K.; Ahmad, O.S.; Guerreiro, A.; Karim, K.; Piletska, E.; Piletsky, S. New potentiometric sensor based on molecularly imprinted nanoparticles for cocaine detection. Biosens. Bioelectron. 2017, 96, 49-54. [CrossRef] [PubMed]

57. Wei, Y.; Zeng, Q.; Hu, Q.; Wang, M.; Tao, J.; Wang, L. Self-cleaned electrochemical protein imprinting biosensor basing on a thermo-responsive memory hydrogel. Biosens. Bioelectron. 2018, 99, 136-141. [CrossRef] [PubMed]

58. Pesavento, M.; Merli, D.; Biesuz, R.; Alberti, G.; Marchetti, S.; Milanese, C. A MIP-based low-cost electrochemical sensor for 2-furaldehyde detection in beverages. Anal. Chim. Acta 2021, 1142, 201-210. [CrossRef]

59. Pesavento, M.; Zeni, L.; De Maria, L.; Alberti, G.; Cennamo, N. SPR-Optical Fiber-Molecularly Imprinted Polymer Sensor for the Detection of Furfural in Wine. Biosensors 2021, 11, 72. [CrossRef] [PubMed]

60. Wren, S.P.; Piletsky, S.A.; Karim, K.; Gascoine, P.; Lacey, R.; Sun, T.; Grattan, K.T.V. Computational Design and Fabrication of Optical Fibre Fluorescent Chemical Probes for the Detection of Cocaine. J. Light. Technol. 2015, 33, 2572-2579. [CrossRef]

61. Shirakawa, H.; Louis, E.J.; MacDiarmid, A.G.; Chiang, C.K.; Heeger, A.J. Synthesis of Electrically Conducting Organic Polymers: Halogen Derivatives of Polyacetylene, (CH)x. J. Chem. Soc. Chem. Commun. 1977, 16, 578-580. [CrossRef]

62. Namsheer, K.; Rout, C.S. Conducting polymers: A comprehensive review on recent advances in synthesis, properties and applications. RSC Adv. 2021, 11, 5659-5697.

63. Kwak, D.; Lei, Y.; Maric, R. Ammonia gas sensors: A comprehensive review. Talanta 2019, 204, 713-730. [CrossRef]

64. Prissanaroon, W.; Ruangchuay, L.; Sirivat, A.; Schwank, J. Electrical conductivity response of dodecylbenzene sulfonic acid-doped polypyrrole films to $\mathrm{SO}_{2}-\mathrm{N}_{2}$ mixtures. Synth. Met. 2000, 114, 65-72. [CrossRef]

65. Korent, A.; Žagar Soderžnik, K.; Šturm, S.; Žužek Rožman, K.; Redon, N.; Wojkiewicz, J.-L.; Duc, C. Facile Fabrication of an Ammonia-Gas Sensor Using Electrochemically Synthesised Polyaniline on Commercial Screen-Printed Three-Electrode Systems. Sensors 2021, 21, 169. [CrossRef] [PubMed]

66. James, D.; Scott, S.M.; Ali, Z.; O’Hare, W.T. Chemical Sensors for Electronic Nose Systems. Microchim. Acta 2005, 149, 1-17. [CrossRef]

67. Deshmukh, S.; Bandyopadhyay, R.; Bhattacharyya, N.; Pandey, R.A.; Jana, A. Application of electronic nose for industrial odors and gaseous emissions measurement and monitoring-An overview. Talanta 2015, 144, 329-340. [CrossRef]

68. Forzani, E.; Zhang, H.; Nagahara, L.A.; Amlani, I.; Tsui, R.; Tao, N. A conducting polymer nanojunction sensor for glucose detection. Nano Lett. 2004, 4, 1785-1788. [CrossRef]

69. Marsella, M.J.; Newland, R.J.; Carroll, P.J.; Swager, T.M. Ionoresistivity as a highly sensitive sensory probe: Investigations of polythiophenes functionalized with calix[4]arene-based ion receptors. J. Am. Chem. Soc. 1995, 117, 9842-9848. [CrossRef] 
70. Sugiyasu, K.; Swager, T.M. Conducting-Polymer-Based Chemical Sensors: Transduction Mechanisms. Bull. Chem. Soc. Jpn. 2007, 80, 2074-2083. [CrossRef]

71. Das, R.; Pattanayak, A.J.; Swain, S.K. Polymer nanocomposites for sensor devices. In Polymer-Based Nanocomposites for Energy and Environmental Applications; Mohammad, J., Mohammad, M.K., Eds.; Woodhead Publishing (Elsevier): Duxford, UK, 2018; Volume 7, pp. 205-218.

72. Baiju, J. Polymer Nanocomposite-Based Electrochemical Sensors and Biosensors In Nanorods and Nanocomposites; Ghamsari, M.S., Dhara, S., Eds.; IntechOpen: Rijeka, Croatia, 2020. [CrossRef]

73. Devi, R.; Thakur, M.; Pundir, C.S. Construction and application of an amperometric xanthine biosensor based on zinc oxide nanoparticles polypyrrole composite film. Biosens. Bioelectron. 2011, 26, 3420-3426. [CrossRef]

74. Zou, L.; Li, Y.; Cao, S.; Ye, B. Gold nanoparticles/polyaniline Langmuir-Blodgett Film modified glassy carbon electrode as voltammetric sensor for detection of epinephrine and uric acid. Talanta 2013, 117, 333-337. [CrossRef]

75. Lu, Y.; Biswas, M.C.; Guo, Z.; Jeon, J.-W.; Wujcik, E.K. Recent developments in bio-monitoring via advanced polymer nanocomposite-based wearable strain sensors. Biosens. Bioelectron. 2019, 123, 167-177. [CrossRef]

76. Costa, P.; Carvalho, M.F.; Correia, V.; Viana, J.C.; Lanceros-Mendez, S. Polymer Nanocomposite-Based Strain Sensors with Tailored Processability and Improved Device Integration. ACS Appl. Nano Mater. 2018, 1, 3015-3025. [CrossRef]

77. Chun, S.; Choi, Y.; Park, W. All-graphene strain sensor on soft substrate. Carbon 2017, 116, 753-759. [CrossRef]

78. Almeida, M.I.G.S.; Cattrall, R.W.; Kolev, S.D. Polymer inclusion membranes (PIMs) in chemical analysis-A review. Anal. Chim. Acta 2017, 987, 1-14. [CrossRef]

79. Kuswandi, B.; Nitti, F.; Almeida, M.I.G.S.; Kolev, S.D. Water monitoring using polymer inclusion membranes: A review. Environ. Chem. Lett. 2020, 18, 129-150. [CrossRef]

80. Silva, N.F.D.; Magalhaes, J.M.C.S.; Barroso, M.F.; Oliva-Telesa, T.; Freire, C.; Delerue-Matos, C. In situ formation of gold nanoparticles in polymer inclusion membrane: Application as platform in a label-free potentiometric immunosensor for Salmonella typhimurium detection. Talanta 2019, 194, 134-142. [CrossRef] [PubMed]

81. Casanueva-Marenco, M.J.; Diaz-de-Alba, M.; Herrera-Armario, A.; Galindo-Riano, M.D.; Granado-Castro, M.D. Design and optimization of a single-use optical sensor based on a polymer inclusion membrane for zinc determination in drinks, food supplement and foot health care products. Mater. Sci. Eng. C 2020, 110, 110680. [CrossRef]

82. Wei, D.W.; Wei, H.; Gauthier, A.C.; Song, J.; Jin, Y.; Xiao, H. Superhydrophobic modification of cellulose and cotton textiles: Methodologies and applications. J. Bioresour. Bioprod. 2020, 5, 1-15. [CrossRef]

83. Xing, R.; Subrahhmanyam, A.V.; Olcay, H.; Qi, W.; Malone, M.F.; van Walsum, G.P.; Pendse, H.P.; Huber, G.W. Production of jet and diesel fuel range alkanes from waste hemicellulose-derived aqueous solutions. Green Chem. 2010, 11, 1873-2068. [CrossRef]

84. Farhat, W.; Venditti, R.A.; Hubbe, M.; Taha, M.; Becquart, F.; Ayoub, A. A Review of Water-Resistant Hemicellulose-Based Materials: Processing and Applications. ChemSusChem 2016, 10, 305-323. [CrossRef]

85. Devaraj, R.D.; Reddy, C.K.; Xu, B. Health-promoting effects of konjac glucomannan and its practical applications: A critical review. Int. J. Biol. Macromol. 2019, 126, 273-281. [CrossRef]

86. Zucca, P.; Fernandez-Lafuente, R.; Sanjust, E. Agarose and Its Derivative as Supports for Enzyme Immobilization. Molecules 2016, 21, 1577. [CrossRef] [PubMed]

87. Singhh, J.; Dartois, A.; Kaur, L. Starch digestibility in food matrix: A review. Trends Food Sci. Technol. 2010, 21, 168-180. [CrossRef]

88. Thakur, B.P.; Singh, R.K.; Handa, A.K.; Rao, M.A. Chemistry and uses of pectin-A review. Crit. Rev. Food Sci. Nutr. 1997, 37, 47-73. [CrossRef]

89. Kaur, N.; Gupta, A.K. Applications of inulin and oligofrutose in health and nutrition. J. Biosci. 2002, 27, 703-714. [CrossRef]

90. Glyn, O.P. Acacia gum (Gum Arabic): A nutritional fibre; metabolism and calorific value. Food Addit. Contam. 1998, 15, 251-264.

91. Muzzarelli, R.A.A. Chitin and its derivatives: New trends of applied research. Carbohydr. Polym. 1983, 3, 53-75. [CrossRef]

92. Agullò, E.; Rodriguez, M.S.; Ramos, V.; Albertengo, L. Present and Future Role of Chitin and Chitosan in Food. Macromol. Biosci. 2003, 3, 521-530. [CrossRef]

93. Ching, S.H.; Bansal, N.; Bhandari, B. Alginate gel particles-A review of production techniques and physical properties. Crit. Rev. Food Sci. Nutr. 2017, 57, 1133-1152. [CrossRef]

94. Sulyman, M.; Haponiuk, J.; Formela, K. Utilization of recycled Polyethylene terephthalate (PET) in Engineering Materials: A Review. IJESD 2016, 7, 100-108. [CrossRef]

95. Close, L.G.; Gilbert, R.D.; Fornes, R.E. Poly (Vinyl Chloride) Degradation-A Review. Polym. Plast. Technol. Eng. 2008, 8, 177-198. [CrossRef]

96. Gonzalez-Tejara, M.J.; Sanchez de la Blanca, E.; Carrillo, I. Polyfuran conducting polymers; Synthesis, properties, and applications. Synth. Met. 2008, 158, 165-189. [CrossRef]

97. Bhardwaj, P.; Grace, A.N. Antistatic and microwave shielding performance of polythiophene-graphene grafted 3-dimensional carbon fibre composite. Diam. Relat. Mater. 2020, 106, 107871. [CrossRef]

98. Li, W.; Huang, H.; Li, Y.; Deng, J. Particles of polyacetylene and its derivatives: Preparation and applications. Polym. Chem. 2014, 5, 1107. [CrossRef]

99. Bavastrello, V.; Bezzerra, T.; Nicolini, C. Conductive Polymers and Gas Sensors. Nanobiotechnology in energy, environment and electronics: Methods and applications. In Pan Stanford Series on Nanobiotechnology; Nicolini, C., Ed.; Jenny Stanford Publishing: London, UK, 2013; Volume 4. 